\title{
KEY IMPACT PARAMETERS FOR APPLICATION OF ALTERNATIVE SOURCE TERM TO KORI UNIT 1
}

\author{
SEUNG-CHAN LEE* \\ KOREA HYDRO \& NUCLEAR POWER Co., \\ Nuclear Engineering \& Technology Institute \\ Jang-dong, Yuseong-gu, Daejeon, 305-343, KOREA \\ "Corresponding author. E-mail : babel21sc@khnp.co.kr \\ Received September 04, 2009 \\ Accepted for Publication May 31, 2010
}

The object of this paper is to identify the key elements that impact a radiation dose at EAB (Exclusion Area Boundary). This study is based on the AST (Alternative Source Terms) as defined in Regulatory Guide 1.183. The LOCA (Loss of Coolant Accident) and the LRA (Locked Rotor Accident) are selected as limiting cases. A sensitivity analysis of accidental behavior with respect to various parameters during LOCA and LRA at Kori Unit 1 is also undertaken for the following objectives: to determine the limiting parameters, to find the impact trend of the radiation dose, and to find the safety margin between AST and TID (Technical Information Document) methodologies. This work confirms that key parameters are particulate removal rate, decontamination factor, iodine chemical form, gap fraction, partitioning factor, and the impact of isotopes group. Comparing TID with AST, the radiation dose of TID is about $80 \%$ greater than that of AST under a LOCA, and about $60 \%$ greater than that of AST for the case of a LRA; thus the safety margin is remarkably increased when the AST is used.

In this work, the sensitivity analysis results are presented in terms of a sensitivity index called the "NDD (Normalized Dose Difference)", which compares the impact of parameters with that of a reference case. These values are derived by using a combination of the leak rate (primary to secondary), iodine chemical form, gap fraction, partitioning factor, spray removal rate, source term, and other variables.

KEYWORDS : TID-14844, AST, NUREG-1465, Kori Unit1, LRA, LOCA.

\section{INTRODUCTION}

Following the promulgation of TID (Technical Information Document)-14844 in 1962, there have been main changes in the regulatory position of the US NRC (United States Nuclear Regulatory Commission) with regard to the use of accident source terms for radiological assessment of DBA (Design-Based Accidents)[1]. The instantaneous source term of TID-14844 was replaced in 1995 with a time-dependent source term of another set of US NRC guidelines called NUREG-1465, which covers the accident source terms for all light water reactor plants. Revisions of the radiological acceptance criteria for reactor site evaluation were also made in 10 CFR Part 100. In particular, the concept of TEDE (Total Effective Dose Equivalent) was incorporated in accordance with the radiation protection standards set forth in the revised version of 10 CFR Part 20[2].

The guidelines on the AST (Alternative Source Term) or RST (Revised Source Term) were made in 2000 after extensive research on the TMI- 2 incident. The source terms in TID-14844 are considered overly conservative and unrealistic. The AST is widely applied in US plants and new plants such as US-EPR for design certification.

The revised regulatory guidelines allow the holder of an operating license issued prior to January 10, 1997 to voluntarily revise the accident source terms used in the radiological consequence analyses of DBA. The guidelines are generally applied in a full or selective manner. In a full application, all the characteristics of the AST (that is, the composition and magnitude of the radioactive material, its chemical and physical form, and the timing of its release) are applied to every aspect of a facility's design. In a selective application, only one or a few of the characteristics of the AST are applied to the design of the facility; this process may entail a reevaluation involving AST radiological analyses for a limited number of cases [3]. Regarding the trend of US NPP (United States Nuclear Power Plants), most of them have been changed from a TID system to AST system in order to refurbish their reactor 
facilities and to increase the safety margin of NPP. Recently, in order to mitigate the radiological consequences of fuel handling accidents, AST application was carried out in Dresden units $2 \& 3$. In that work, if using the AST, the utility of Dresden NPP concludes that their technical specifications to support the normal reactor building exhaust stack and control room emergency filter system operability may not be necessary after the reactor shut down period. And then, TS (Technical Specification) revision of Dresden units $2 \& 3$ was subsequently licensed from the USNRC through the AST application calculation [4].

Other experiments involving AST were carried out by Porcheron et al in 2007. They mixed nitrogen gas with aerosols from equipment such as control rods and ducts, whose size distribution is less than $100 \mathrm{um}$, with a material average density of $3.2 \mathrm{~g} . \mathrm{cm}^{-3}$. These experiments were carried out using a TOSQAN facility. The TOSQAN facility was established to study the effects of water spray activation on aerosol washout. Using the facility, experiments on the physical effects for detailed features of the spray, the spray water droplet distribution, and the aerosol distribution were carried out from 2003 to 2007 $[5,6]$.

Considering the study such as Porcheron's work and the current trend of applying the AST in US nuclear power plants, it is expected that the AST will be applied to domestic operating nuclear power plants in the near future. To establish a methodology for the assessment of calculation uncertainty and the application of AST, and to meet future technical demands, it is necessary to determine the advantages and the key elements of AST.

In this paper, using TID and AST, safety analyses of LOCA and LRA are carried out in order to determine which plant design parameters are affected at the Kori Unit 1 plant in the Republic of Korea. The basic aim is to gain insight into the effects of applying the TID and AST to Korean plants. In addition, a new concept for an uncertainty assessment of RADTRAD code using Monte Carlo simulation is introduced in this study. Furthermore, the extensive analyses are carried out to show the effects of various reactor design parameters and calculation models during accidents. The assumptions and initial conditions of the FSAR (Final Safety Analysis Report) of Kori Unit 1 are used for the sensitivity analysis. The corresponding analysis results are reassessed in a conservative and reliable manner in terms of the key parameters of both the TID methodology and the AST methodology [7-9].

\section{METHODS}

\subsection{Source Term Methodology for TID and AST}

The AST methodology incorporates a new source term and the total effective dose equivalent as the new radiological singular criterion. In terms of analysis, the new source term of AST differs significantly from that of TID-14844, particularly with respect to radionuclide composition, release fractions and timing of release phases, iodine chemical form, and removal mechanisms.

The TID-14844 source term considers just two

Table 1. Regulatory Bases for TID-14844 and Alternative Source Term [1-3, 7-10]

\begin{tabular}{|c|c|}
\hline CURRENT METHODOLOGY (TID-14844) & NEW METHODOLOGY (AST) \\
\hline $\begin{array}{l}\text { - Source term: TID } 14844 \text { (1962) } \\
\text { - Dose factors: whole body and thyroid (ICRP-2) } \\
\text { - Regulatory requirements: } \\
\text { - } 10 \text { CFR } 100.3 \text { (EAB, LPZ) } \\
\text { - } 10 \text { CFR } 100.11 \text { (Limits EA, LPZ) } \\
\text { - } 10 \text { CFR } 50 \text { GDC19-Ap.A (CR) } \\
\text { - } 10 \text { CFR } 50.49 \text { (QA) } \\
\text { - Guides: } \\
\text { - R.G. } 1.3 \text { (LOCA), R.G. } 1.5 \text { (MSLB), R.G. } 1.77 \text { (CRDA), R.G. } \\
\text { 1.25 (FHA, DBA) } \\
\text { - R.G. } 1.89 \text { (QA) } \\
\text { - R.G. } 1.145 \text { (X/Q in EAB \& LPZ) }\end{array}$ & $\begin{array}{l}\text { - Source term: NUREG-1465 (1995) } \\
\text { - Dose conversion factors: total effective dose equivalent } \\
\text { (ICRP-30/FGR } 11 \text { and 12) } \\
\text { - Regulatory requirements: } \\
\text { - } 10 \text { CFR 100.3 (EAB, LPZ) } \\
\text { - } 10 \text { CFR 50.67 (Limits TEDE, EAB, LPZ, CR) } \\
\text { - } 10 \text { CFR } 50.49 \text { (QA) } \\
\text { - Guides: } \\
\text { - R.G. } 1.183 \text { (DBA) } \\
\text { - R.G. } 1.183 \text { (DBA), R.G. } 1.89 \text { (QA) } \\
\text { - R.G. } 1.145 \text { ( X/Q in EAB \& LPZ) }\end{array}$ \\
\hline
\end{tabular}


categories of radionuclides, such as noble gas and iodine, whereas the AST, which is based on the chemical behavior similarity, categorizes the release of fission products into eight-nuclide-groups. Activity release in TID-14844 is assumed to occur instantaneously, immediately after the onset of an accident. In contrast, the activity release in the AST is assumed to occur in two phases over a period of several hours, with the onset of the main core damage occurring after 30 minutes at pressurized water reactors.

The new methodology replaces the following regulatory guidelines and requirements for evaluating the radiological consequences of a DBA and the dose limits for an EAB (Exclusion Area Boundary), LPZ (Low Population Zone), and CR (Control Room). Table 1 compares the old and the new methodologies.

\subsection{General Description of Selected Accidents in this Work}

This section covers the scenario of the selected events (LOCA, LRA) for the safety analyses in this work.

\subsubsection{Loss of Coolant Accident}

Kori Unit 1, presented in this study, is a Westinghouse type nuclear power plant and is governed by the Westinghouse definition of a LOCA. According to the accident scenario, the system goes through a double-ended rupture of cold lag or of hot lag in the RCS(Reactor Coolant System). Depression of the RCS then causes the pressure drop in the pressurizer. And then the reactor trip signal is subsequently triggered. Before the break occurs, the reactor is assumed to be running at full power.

The accident goes through the following steps [2]:

a) Blow-down phase start - the accumulator begins to inject coolant water into the reactor coolant loops (RCS depressurizes 700 psi).

b) The flow from the accumulator at the intact loop of the RCS cannot reach the core during the ECCS (Emergency Core Cooling System) bypass.

c) ECCS flows out toward the break point until reaching the equilibrium pressure between RCS and containment (Blow-down phase end).

d) Refill - refilling cooling water at the lower plenum of the reactor vessel.

e) Re-flood phase - the reactor vessel is filled with water (maintaining room temperature).

\subsubsection{Locked Rotor Accident}

The LRA analysis is based on the postulation of an instantaneous seizure of a RCP (Reactor Coolant Pump) rotor. This problem can cause a reactor trip on the subsequent low flow signal.

This accident goes through the following steps [2]:

a) After the trip, the reactor coolant water expands due to the heat stored in fuel rods. b) Reduction of heat transfer in the steam generator.

c) Turbulence in the pressurizer due to an increase in pressure throughout the reactor coolant system.

d) Actuation of the automatic spray system; SG PORV (Steam Generator power-operated relief valves) opens and pressurizer safety valves open.

e) System damage (65\% of fuel rods on the basis of a conservative estimation).

f) The release of gap activity (radionuclides released into the environment via leaking SG tubes and SG PORV $[2,7]$.

\subsection{Analytical Assumption for AST Methodology}

In this section, prior to the analysis of the selected events, the necessary assumptions are introduced.

\subsubsection{Loss of Coolant Accident}

The following assumptions are used to calculate the radiological consequences of an LOCA at Kori Unit 1:

a) If the $\mathrm{pH}$ of a sump or suppression pool is controlled at a value of 7 or greater, the chemical form of radioiodine released to the containment is assumed to be $95 \%$ cesium iodide (CsI), $4.85 \%$ elemental iodine, and $0.15 \%$ organic iodide.

b) The release time is 2 hours (gap release and early-invessel).

c) The activity released from the core during each release phase should be modeled in an increasing linear fashion for the duration of the accident.

d) According to Regulatory Guide $1.183,100 \%$ of the core inventory of noble gases and $40 \%$ of iodine are released from the core into the containment.

\subsubsection{Locked Rotor Accident}

The following assumptions are used to calculate the radiological consequences of a LRA at Kori Unit 1[2]:

a) The core inventory is based on a DBA power level of $1,758 \mathrm{Mw}$, which is $102 \%$ of the rated thermal power.

b) $65 \%$ of the fuel is damaged and failed during the initiation of the LRA.

c) According to Regulatory Guide $1.183,5 \%$ of the core inventory of noble gases, as well as iodine $(8 \%)$ and krypton $(10 \%)$ are released from the fuel gap.

d) Iodine is $97 \%$ particulates and $3 \%$ organic.

e) SG PORV release lasts 8 hours; the core residual heat can thereafter be removed by an auxiliary feed-water system.

\subsection{Application of Source Term and Reference Conditions}

This section covers all the information of the reference case for the application of the alternative source term of NUREG-1465, as well as the potential impact of each type of application and considerations of each type or case of 
application.

In Korea, the DBA and source terms are based on Regulatory Guide 1.4 (U.S. Nuclear Regulatory Commission, 1974). Furthermore, the radioiodine activities are based on the 1959 guidelines of the ICRP-2 (International Commission on Radiological Protection 2) $[8,10,11]$.

In this study, using the RADTRAD (Radionuclide Transport, Removal, and Dose) 3.03, a re-analysis is carried out by the use of the same inputs given in the FSAR of Kori Unit 1. This work is used for confirming the feasibility of the computer code RADTRAD 3.03, and to establish a reference value of the radiation dose used in the sensitivity analysis.

Table 2 is the reference case for the reanalysis; the input data are the same as those given in the FSAR of Kori Unit 1. For a large-break LOCA in the DBA, the pathways of radioactive release are as follows:

1) Containment volume purge (the exchange between sprayed and unsprayed)

2) Containment leakage (from the containment to the environment)

3) Re-circulation leakage (during sump re-circulation)

Table 3 shows the main parameters of a LRA. In order to analyze the sensitivity for the parameters of the LRA, the design reference values in Table 3 are used in conjunction with the TID and AST methodologies.

\subsection{Calculations}

In this section, the computer code calculation methodology and the calculation model are introduced.

RADTRAD code in this work was used for predicting and estimating the radiological consequences under LOCA and LRA as representative cases of design basis accidents at Kori Unit 1 . This code was developed by the USNRC and can evaluate doses at offsite locations such as the EAB (Exclusion Area Boundary), LPZ (Low Population Zone), and the CR (Control Room). For the radiological

Table 2. Main Parameters Used for the Reference Case of LOCA [7]

\begin{tabular}{|c|c|c|c|}
\hline System & Design Parameters & Unit & Values \\
\hline Containment & $\begin{array}{l}\text {-Free volume } \\
\text { Design leak rate } \\
\text { - 0 24 hours } \\
\text { - 1 30 days } \\
\text { - Sprayed region } \\
\text { - Unsprayed region } \\
\text { Spray removal rate } \\
\text { - Elemental } \\
\text { - Particulate } \\
\text { Mixing rate } \\
\text { - Turnovers of unsprayed region } \\
\text { - Containment volume purge rate }\end{array}$ & $\begin{array}{c}\mathrm{ft}^{3} \\
\% / \text { day } \\
\% / \text { day } \\
\% \\
\% \\
\mathrm{hr}^{-1} \\
\mathrm{hr}^{-1} \\
\\
\mathrm{hr}^{-1} \\
\mathrm{cfm}^{2}\end{array}$ & $\begin{array}{c}1.450 \times 10^{6} \\
0.1 \\
0.05 \\
75 \\
25 \\
\\
16.3 \\
3.21 \\
\\
2 \\
2.000 \times 10^{4}\end{array}$ \\
\hline $\begin{array}{l}\text { Auxiliary } \\
\text { Building }\end{array}$ & $\begin{array}{l}\text { Iodine characteristic } \\
\text {-Iodine Partitioning } \\
\text {-Re-circulation loop leakage } \\
\text { ECCS room \& HVAC system } \\
\text {-Flow rate } \\
\text {-Volume covered by HVAC system }\end{array}$ & $\begin{array}{c}\% \\
\mathrm{cfm} \\
\mathrm{cfm}^{3}\end{array}$ & $\begin{array}{c}10 \\
0.17 \times 10^{-2} \\
\\
3,600 \\
1.12 \times 10^{6}\end{array}$ \\
\hline $\mathrm{X} / \mathrm{Q}$ & $\begin{array}{l}\text { EAB }(700 \mathrm{~m}) \\
-0 \sim 2 \text { hours }\end{array}$ & $\mathrm{sec} / \mathrm{m}^{3}$ & $6.90 \times 10^{-4}$ \\
\hline
\end{tabular}

ECCS : Emergency Core Cooling System

HVAC: Heating, Ventilation \& Air Conditioning System

$\mathrm{X} / \mathrm{Q}$ : Atmospheric dispersion factor(Air diffusion factor) 
consequences analysis, this code has a well-developed model of the containment facility and can estimate not only the flow of radionuclides from the source release point to offsite but also their removal mechanism.

In these cases, the users may either select the formula in the SRP (Standard Review Plan) model or activate the RADTRAD model. RADTRAD models are summarized by three decontamination mechanisms: (a) decontamination due to spray, (b) decontamination due to natural deposition, and (c) decontamination due to the surface of pipes. According to the USNRC's validation report, the accuracy of this code is known to be within $10 \%$ owing to its conservative assumptions; however, RADTRAD can predict radiation dose very accurately under the condition of full application of real variables. In the case of preliminary tests using USNRC's example and Braidwood Nuclear Power Plant, the results of RADTRAD accuracy are within $1.0 \%$ (See Table 11 in Results and Discussion).

\subsubsection{Description of Computer Code}

For the evaluation of radiological consequences, RADTRAD 3.03 is used to model the following:

a) Two types of releases from the RCS into the containment: the instantaneous releases specified in TID-14884 and in Regulatory Guide 1.3, and the more realistic source terms specified in NUREG-1465 and in Regulatory Guide 1.183.

b) A variety of processes that can attenuate or transport radionuclide. Sprays and natural deposition mechanisms can be modeled to remove radioactive material from the compartment atmospheres.

c) The radionuclide flow between the compartment atmospheres (These flows can be simulated through filters, piping or unfiltered options. The models for flow-through piping can optionally account for aerosol deposition and iodine chemical behavior).

d) Radioactive decay and daughter in-growth.

\subsubsection{Calculation Models}

The radiological consequences of an accident in a nuclear reactor depend on the quantity of radioactive material that escapes into the environment or enters the control room. The RADTRAD code is designed to calculate the off-site dose by using its own code as a model. The code uses source terms from both TID-14844 and AST of NUREG-1465. All of the code calculations are based on the basic equation for radionuclide transport and the removal mechanism for all compartments.

\subsubsection{Basic RADTRAD Calculation Model}

The governing equation of RADTRAD covers all source terms for the number of nuclide atoms $n$, in a

Table 3. Main Parameters Used for the Reference Case of LRA [7]

\begin{tabular}{|c|c|c|c|}
\hline \multicolumn{2}{|c|}{ Design Parameters } & Unit & Values \\
\hline Thermal Power & $102 \%$ & MWth & 1758.0 \\
\hline RCS & Primary Coolant & $\mathrm{ft}^{3}$ & 6179.9 \\
\hline Steam Generator & Secondary Coolant & $\mathrm{ft}^{3}$ & 5745 \\
\hline Containment & Building & $\mathrm{ft}^{3}$ & $1.45 \times 10^{6}$ \\
\hline $\begin{array}{l}\text { Leakage between primary } \\
\text { to secondary }\end{array}$ & Intact SG & gpm & 0.5 \\
\hline $\begin{array}{l}\text { Leakage between primary } \\
\text { to secondary }\end{array}$ & Faulted SG & gpm & 0.5 \\
\hline \multirow{4}{*}{$\begin{array}{l}\text { Thermal hydraulic } \\
\text { parameters }\end{array}$} & Fuel Cladding Failure & $\%$ & 65 \\
\hline & Fuel Melting & $\%$ & 0 \\
\hline & Total Steam Release through SG PORV & $\mathrm{lbm}$ & $\begin{array}{l}258,600(0-2 \text { hours }) \\
569,400(2-8 \text { hours })\end{array}$ \\
\hline & Ending time & hour & 8 \\
\hline
\end{tabular}

RCS : Reactor Coolant System

SG: Steam Generator

PORV : Power Operated Release Valve 
compartment I, during a given time step $\mathrm{m}$. The equation is used for tracking radioisotopes' behavior and calculating the source inventory of the radioisotopes moving from compartment to compartment. The equation is expressed as follows $[8,12]$ :

$$
\begin{aligned}
& \frac{d}{d t} N_{n, i}^{m}=\sum_{v=1}^{n-1} \beta_{n, v} N_{v, i}^{m} \lambda_{v}+S_{n, i}^{m} \\
& -\left[\sum_{\substack{j=I \\
j \neq i}}^{L}\left[F_{i, j(c o n v)}^{m}+\frac{Q_{i, j(s)}^{m}}{V o l_{i}}+\frac{Q_{i, j(p)}^{m}}{V o l_{i}}\right]+\lambda_{n}+\lambda_{s p r, n}^{m}(t)+\lambda_{d e p, n}^{m}(t)+\frac{\eta_{n i, j}^{m}}{100} F_{i, j(\text { forced })}^{m}\right] N_{n, j}^{m} \\
& +\left[\sum_{\substack{j=I \\
j \neq i}}^{L}\left(1-\frac{\eta_{n i, j}^{m}}{100}\right) F_{i, j(\text { forced })}^{m}+F_{i, j(\text { conv })}^{m}+\frac{Q_{i, j(s)}^{m}}{V o l_{i} D F_{n(s)}^{m}}+\frac{Q_{i, j(p)}^{m}}{V o l_{i} D F_{n(s)}^{m}}\right] N_{n, j}^{m}
\end{aligned}
$$

$$
\lambda_{n}=\ln (2) / T_{n}^{1 / 2}
$$

$N_{n, i}^{m} \quad=$ number of atoms of nuclide $\mathrm{n}$ in compartment $\mathrm{I}$ during time step $\mathrm{m}$

$\beta_{n, v}=$ fraction of nuclide $\mathrm{v}$ that decays to nuclide $\mathrm{n}$ (dimensionless)

$\lambda_{n} \quad=$ radiological decay constant for nuclide $\mathrm{n}\left(\mathrm{s}^{-1}\right)$

$T_{n}^{I / 2} \quad=$ half life of nuclide $\mathrm{n}(\mathrm{s})$

$F_{i, j(c o n v)}^{m}=$ volume-normalized convective (leakage) air flow rate from compartment $\mathrm{j}$ to $\mathrm{I}\left(\mathrm{s}^{-1}\right)$

$F_{i, j(\text { forced })}^{m}=$ volume-normalized forced air flow rate from compartment $\mathrm{j}$ to $\mathrm{I}\left(\mathrm{s}^{-1}\right)$

$\mathrm{L} \quad=$ number of compartments defined in the plant model

$Q_{i, j(s)}^{m}=$ volumetric flow rate from compartment $\mathbf{j}$ to $\mathbf{I}$ through a suppression pool $\left(\mathrm{m}^{3} / \mathrm{s}\right)$

$Q_{i, j(p)}^{m}=$ volumetric flow rate from compartment $\mathrm{j}$ to $\mathbf{I}$ through a pipe $\left(\mathrm{m}^{3} / \mathrm{s}\right)$

$V_{\text {ol }}=$ volume of compartment $\mathrm{k}\left(\mathrm{m}^{3}\right)$

$D F_{n(s)}^{m}=$ suppression pool decontamination factor for nuclide $\mathrm{n}$ during time step $\mathrm{m}$ (dimensionless)

$D F_{n(p)}^{m}=$ piping decontamination factor for nuclide $\mathrm{n}$ during time step $\mathrm{m}$ (dimensionless)

$\lambda_{s p r, n}^{m}(t)=$ time-dependent spray removal coefficient for nuclide $\mathrm{n}\left(\mathrm{s}^{-1}\right)$

$\lambda_{d e p, n}^{m}(t)=$ time-dependent natural deposition removal rate coefficient $\left(\mathrm{s}^{-1}\right)$

$S_{n, i}^{m} \quad=$ source injection rate of nuclide $\mathrm{n}$ to compartment I during time step $\mathrm{m}$ (atoms/s)

$\eta_{n: i, j}^{m}=$ filter efficiency associated with nuclide $\mathrm{n}$ and the pathway from $\mathrm{j}$ to I ( $\%$ )

Equations (1) and (2) are solved by RATRAD with the assumption that all the nuclide atoms can be grouped according to their chemical form and transport similarities. Thus, four transport groups were used: noble gases, elemental iodine, organic iodine, and aerosols.

\subsubsection{Calculation Models for Removal Phenomena of RADTRAD}

The mechanism for removing radioactive material from the atmosphere of each compartment includes sprays, natural deposition, leakage, natural and forced convection, and filters. The driving routine for determining an individual removal phenomenon was implemented in COEFFS, the calculation module of RADTRAD. RADTRAD includes a power model (spray removal model), Henry's model (natural deposition model), and a thermal power model. These models are sufficient to simulate iodine behavior in a containment building. In this work, the RADTRAD models for sprays and containment deposition are evaluated by correlating the results of more detailed models using a Monte Carlo uncertainty analysis.

Generally, RADTRAD models use the same equations as the US NRC SRP (Standard Review Plan) model. The RADTRAD calculation model by spray removal is delineated as follows:

$$
\lambda_{p}=\frac{1.5 h F}{V}\left(\frac{E}{D}\right): \text { particulates }
$$

where $\mathrm{F}=$ total water flow rate, $\mathrm{h}=$ fall distance of spray drops, $\mathrm{V}=$ containment volume, and $\mathrm{E} / \mathrm{D}=$ capture efficiency divided by the droplet diameter.

In NUREG/CR-5966 of the US NRC report, for droplets $1000 \mathrm{um}$ in diameter a value of $E / D=10 \mathrm{~m}^{-1}$ has been recommended. This recommendation is valid for Kori Unit 1, because the droplet size distribution of Kori Unit 1 ranges from 900um to $1200 \mathrm{um}$. This value is further recommended to be reduced to $1 \mathrm{~m}^{-1}[13,14]$. Once the mass fraction of aerosol remaining in the containment, $\mathrm{m}_{\mathrm{f}}$, has been reduced to 0.02 . Values of $\lambda_{p}$ cited here in units of $\mathrm{hr}^{-1}$ can be converted to E/D ratios in units of $\mathrm{m}^{-1}$ by:

$$
\frac{E}{D}\left(m^{-1}\right)=\frac{\lambda_{p}\left(\mathrm{hr}^{-1}\right) 0.01852}{Q\left(\mathrm{~cm}^{3} / \mathrm{cm}^{2}-s\right)}
$$

The decontamination coefficient $\lambda_{p}$ varies with the fraction of aerosol mass remaining in the containment, $\mathrm{m}_{\mathrm{f}}$. Here, $\lambda_{\mathrm{p}}$ decreases approximately linearly with $\mathrm{m}_{\mathrm{f}}$ for values of $m_{\mathrm{f}}$ greater than about 0.1 . For smaller values of $\mathrm{m}_{\mathrm{f}}, \lambda_{\mathrm{p}}$ approaches a constant value. The change in $\lambda_{\mathrm{p}}$ with $\mathrm{m}_{\mathrm{f}}$ is related in a very straightforward manner with the results of the change in size distribution of aerosol remaining in the containment. From these results, if $\lambda_{p}$ is selected, E/D can be derived from the correlation with the spray flux Q (volumetric flow per cross sectional area), as shown in equation (4). The correlation is valid for a 
fall distance of spray drops between 5 and 50 meters and a spray flux Q between 0.00001 and $0.0025\left(\mathrm{~m}^{3} / \mathrm{m}^{2} \cdot \mathrm{sec}\right)$. In this study, a fall distance of 29 meters is used for calculating $\lambda_{\mathrm{p}}$ of Kori Unit 1.

The natural deposition model of RADTRAD is based on the theory of condensation due to the spray droplet and the wall surface. This model calculation is carried out by the CONTAIN module of RADTRAD. Generally, the CONTAIN module is used for calculating the particle deposition from turbulent flows, gravitational settling, and deposition velocity.

\subsubsection{Calculation Models for Removal Phenomena in NRC SRP Model}

In this work, the US NRC SRP spray model is compared with Henry's model (natural deposition model) and the power model (spray removal model) of RADTRAD. The effectiveness of the spray against elemental iodine and particulate iodine is chiefly introduced for determination and calculation of the spray effects. In these models, the rate of solution surface created per unit gas volume in the containment atmosphere can be estimated as 6F/VD, where $\mathrm{F}$ is the volume flow rate of the spray pump, $\mathrm{V}$ is the containment building net free volume, and D is the massmean diameter of the spray drops. The first-order removal coefficient by spray, $\lambda_{s}$, may be taken to be equation (5), where $\mathrm{Kg}$ is the gas-phase mass-transfer coefficient and $\mathrm{T}$ is the time of fall of the drops, which may be estimated by the ratio of the average fall height to the velocity of the mass-mean drop. This equation represents a first-order approximation if a well-mixed droplet model is used for the spray efficiency. Equation (5) is valid for $\lambda_{s}$ values equal to or greater than 10 per hour. $\lambda_{s}$ must be limited to 20 per hour in order to prevent extrapolation beyond the existing data for boric acid solutions with a $\mathrm{pH}$ of 7 . For $\lambda_{\mathrm{s}}$ values less than 10 per hour, analyses using a more sophisticated expression are recommended.

$$
\begin{aligned}
& \lambda_{s}=\frac{6 K_{g} T F}{V D}: \text { elemental } \\
& \lambda_{p}=\frac{3 h F E}{2 V D}: \text { particulates }
\end{aligned}
$$

The first-order removal coefficient for particulates, $\lambda_{\mathrm{p}}$, can be determined by equation (6) using the method described in SRP 6.5.2. In equation (6), $h$ is the spray drop fall height, $\mathrm{V}$ is the containment building net free volume, $\mathrm{F}$ is the spray flow, and $\mathrm{E} / \mathrm{D}$ is the ratio of a dimensionless collection efficiency $\mathrm{E}$ to the average spray drop diameter D. Since the removal of particulate material strongly depends on size distributions of the particles and the spray droplets, using the combination of parameters, it is conservative to assume E/D to be 10 per meter initially. This specific features of spray are based on the SRP 6.5.2.

\subsubsection{Release Timing and Gap Fraction of Source Term}

The conditions of AST application used in this analysis are derived from the guidelines of Reg. Guide 1.183. As source term data, a list of 60 core isotopic nuclides is included in the RADTRAD NIF (Nuclides Inventory File). The release fractions associated with all of these nuclide groups are included in the RADTRAD "RFT (Release Fraction and Timing)" files, which is the same information shown in Table 4.

Table 4 summarizes the AST and TID characteristics, the release timing of the source term, and iodine formation for non-LOCA and LOCA.

The release of radio nuclides during the LRA includes only one condition of a gap release for 30 minutes after

\begin{tabular}{|c|c|c|c|c|}
\hline & TID-14844 & \multicolumn{3}{|c|}{ AST } \\
\hline Composition & $\begin{array}{l}\text { Noble gases } \\
\text { and Iodine }\end{array}$ & \multicolumn{3}{|c|}{$\begin{array}{l}\text { Noble gases, halogens, alkali metals, noble metals, lanthanides, } \\
\text { cerium and tellurium groups }\end{array}$} \\
\hline \multirow{3}{*}{$\begin{array}{l}\text { Timing of } \\
\text { Release }\end{array}$} & & In phases & PWR Duration & BWR Duration \\
\hline & \multirow{2}{*}{ Immediate } & Gap release & $30 \mathrm{~s} \sim 30 \mathrm{~min}$ & $2 \mathrm{~min} \sim 30 \mathrm{~min}$ \\
\hline & & Early in-vessel & $30 \mathrm{~min} \sim 1.3 \mathrm{~h}$ & $30 \mathrm{~min} \sim 1.5 \mathrm{~h}$ \\
\hline $\begin{array}{l}\text { Iodine } \\
\text { formation }\end{array}$ & Elemental form (91\%) & & ticulate form (95 & \\
\hline
\end{tabular}

Table 4. AST and TID Characteristics [12] 
the accident. Otherwise, in the case of the LOCA, the release of radionuclides uses the gap release and early invessel as full applications of AST in Table 4.

According to Regulatory Guide $1.183,5 \%$ of iodine and noble gas in the core inventory is assumed to be in the fuel-clad gap, excluding I-131(8\%) and $\mathrm{Kr}-85(10 \%)$.

Otherwise, $12 \%$ of the cesium and rubidium is assumed to be in the fuel-clad gap. All of the gap activity in the damaged fuel is released into the RCS and mixed homogeneously. Table 5 shows the gap activity in this work for analysis of the sensitivity of the gap fraction. These activity release fractions are included in the
RADTRAD code through a RFT (Release Fractions and Timing) file.

\subsubsection{Partitioning Fractions and Pathway}

Figs. 1 and 2 show the release pathways of radioactivity from inside Kori Unit 1 to the environment (shown as "ENV" in Fig. 1 and 2) as a result of LOCA and LRA [2, 7].

For a LOCA, the fission products from $100 \%$ of the melted fuel will be released into the RCS, and the noble gases (100\%) and iodine (40\%) from the RCS (Reactor

Table 5. Gap Fraction and Activity in Each Case of Regulatory Guides [1, 2, 15]

\begin{tabular}{|c|c|c|c|c|c|c|c|}
\hline \multirow[t]{2}{*}{ Radionuclide } & \multirow{2}{*}{$\begin{array}{c}\text { RCS } \\
\text { Inventory } \\
\text { (Ci) }\end{array}$} & \multicolumn{2}{|c|}{ FSAR of Kori Unit 1} & \multicolumn{2}{|c|}{ R.G. 1.183} & \multicolumn{2}{|c|}{ R.G. 1.25} \\
\hline & & Gap fraction & Activity $(\mathrm{Ci})$ & Gap fraction & Activity (Ci) & Gap fraction & Activity (Ci) \\
\hline $\mathrm{I}-131$ & $4.45 \mathrm{E}+07$ & $1.830 \%$ & $8.20 \mathrm{E}+05$ & $10.000 \%$ & $4.45 \mathrm{E}+06$ & $10.000 \%$ & $4.45 \mathrm{E}+06$ \\
\hline $\mathrm{I}-132$ & $6.75 \mathrm{E}+07$ & $0.204 \%$ & $1.40 \mathrm{E}+05$ & $5.000 \%$ & $3.38 \mathrm{E}+06$ & $10.000 \%$ & $6.75 \mathrm{E}+06$ \\
\hline $\mathrm{I}-133$ & $9.97 \mathrm{E}+07$ & $0.611 \%$ & $6.10 \mathrm{E}+05$ & $5.000 \%$ & $4.99 \mathrm{E}+06$ & $10.000 \%$ & $9.97 \mathrm{E}+06$ \\
\hline $\mathrm{I}-134$ & $1.17 \mathrm{E}+08$ & $0.126 \%$ & $1.50 \mathrm{E}+05$ & $5.000 \%$ & $5.85 \mathrm{E}+06$ & $10.000 \%$ & $1.17 \mathrm{E}+07$ \\
\hline $\mathrm{I}-135$ & $9.05 \mathrm{E}+07$ & $0.348 \%$ & $3.10 \mathrm{E}+05$ & $5.000 \%$ & $4.53 \mathrm{E}+06$ & $10.000 \%$ & $9.05 \mathrm{E}+06$ \\
\hline $\mathrm{Xe}-131 \mathrm{~m}$ & $3.40 \mathrm{E}+05$ & $0.220 \%$ & $7.50 \mathrm{E}+03$ & $5.000 \%$ & $1.70 \mathrm{E}+04$ & $10.000 \%$ & $3.40 \mathrm{E}+04$ \\
\hline Xe-133 & $1.03 \mathrm{E}+08$ & $1.490 \%$ & $1.50 \mathrm{E}+06$ & $5.000 \%$ & $5.15 E+06$ & $10.000 \%$ & $1.03 \mathrm{E}+07$ \\
\hline $\mathrm{Xe}-133 \mathrm{~m}$ & $2.61 \mathrm{E}+06$ & $0.982 \%$ & $2.60 \mathrm{E}+04$ & $5.000 \%$ & $1.31 \mathrm{E}+05$ & $10.000 \%$ & $2.61 \mathrm{E}+05$ \\
\hline $\mathrm{Xe}-135$ & $2.81 \mathrm{E}+07$ & $0.408 \%$ & $1.10 \mathrm{E}+05$ & $5.000 \%$ & $1.41 \mathrm{E}+06$ & $10.000 \%$ & $2.81 \mathrm{E}+06$ \\
\hline $\mathrm{Xe}-135 \mathrm{~m}$ & $2.76 \mathrm{E}+07$ & $0.069 \%$ & $1.80 \mathrm{E}+04$ & $5.000 \%$ & $1.38 \mathrm{E}+06$ & $10.000 \%$ & $2.76 \mathrm{E}+06$ \\
\hline Xe-138 & $9.05 \mathrm{E}+07$ & $0.072 \%$ & $6.50 \mathrm{E}+04$ & $5.000 \%$ & $4.53 \mathrm{E}+06$ & $10.000 \%$ & $9.05 \mathrm{E}+06$ \\
\hline $\mathrm{Kr}-85$ & $5.00 \mathrm{E}+05$ & $26.500 \%$ & $1.30 \mathrm{E}+05$ & $8.000 \%$ & $4.00 \mathrm{E}+04$ & $30.000 \%$ & $1.50 \mathrm{E}+05$ \\
\hline $\mathrm{Kr}-85 \mathrm{~m}$ & $1.99 \mathrm{E}+07$ & $0.281 \%$ & $5.60 \mathrm{E}+04$ & $8.000 \%$ & $1.59 \mathrm{E}+06$ & $30.000 \%$ & $5.97 \mathrm{E}+06$ \\
\hline $\mathrm{Kr}-87$ & $3.83 \mathrm{E}+07$ & $0.152 \%$ & $5.80 \mathrm{E}+04$ & $5.000 \%$ & $1.92 \mathrm{E}+06$ & $10.000 \%$ & $3.83 \mathrm{E}+06$ \\
\hline $\mathrm{Kr}-88$ & $5.46 \mathrm{E}+07$ & $0.224 \%$ & $1.20 \mathrm{E}+05$ & $5.000 \%$ & $2.73 E+06$ & $10.000 \%$ & $5.46 \mathrm{E}+06$ \\
\hline
\end{tabular}

Table 6. Nuclides Released to Environment in this Analysis

\begin{tabular}{c|c|c|c|c|c|c}
\hline $\begin{array}{c}\text { Time } \\
\text { Interval } \\
(\mathrm{hrs})\end{array}$ & $\begin{array}{c}\text { Total Steam } \\
\text { Mass } \\
(\mathrm{lbm})\end{array}$ & $\begin{array}{c}\text { Iodine } \\
\text { Part. } \\
\text { Fraction }\end{array}$ & $\begin{array}{c}\text { Cesium } \\
\text { Part. } \\
\text { Fraction }\end{array}$ & $\begin{array}{c}\text { Noble Gas } \\
\text { Part. } \\
\text { Fraction }\end{array}$ & $\begin{array}{c}\text { Steam Release } \\
\text { Rate for Iodine } \\
(\mathrm{cfm})\end{array}$ & $\begin{array}{c}\text { Steam Release } \\
\text { Rate for Cesium } \\
(\mathrm{cfm})\end{array}$ \\
\hline $0-2.0$ & 258,600 & 0.01 & 0.0055 & 1.0 & 0.9602 & 0.52811 \\
$2.0-8.0$ & 569,400 & 0.01 & 0.0055 & 1.0 & 0.2535 & 0.1394 \\
$8.0-40$ & 0 & 0.01 & 0 & 0 & 0 & 0 \\
\hline
\end{tabular}


Coolant System) will be released into the containment area.

For LRA, the postulated leak rate of Kori Unit 1 is 0.5 gpm per SG (for a total of $1.0 \mathrm{gpm}$ ). The release to the environment (ENV) is related to steam from the intact SG PORV and direct release from the failed SG PORV.

The partitioning fraction of iodine is 0.01 from R.G. 1.183. For other nuclides, the partitioning fraction (or partitioning factor) is 0.0055 . Generally, partitioning fraction is defined as the ratio between the gas phase and the liquid phase of iodine. Table 6 shows the steam release rate to the environment, which is used for calculating the radiation dose.

\subsubsection{Dose Calculations}

The target of calculation is focused on determining the radiation dose at EAB under LOCA and LRA. The RADTRAD code uses a combination of Tables 4 through 6 in the previous section, and its numerical models of source term reduction phenomena to determine the dose at EAB for a given accident scenario. The code system also provides the inventory, decay chain, and dose conversion factor tables needed for the dose calculation. The information of Tables 2 and 3 in the previous section is used as input for calculating the radiation dose.

\subsection{Estimation of Code Uncertainty and Accuracy}

In these works, all processes are carried out by RADTRAD code. In order to estimate the uncertainty, a Monte Carlo Simulation is carried out using Box-Muller's algorithm [16].

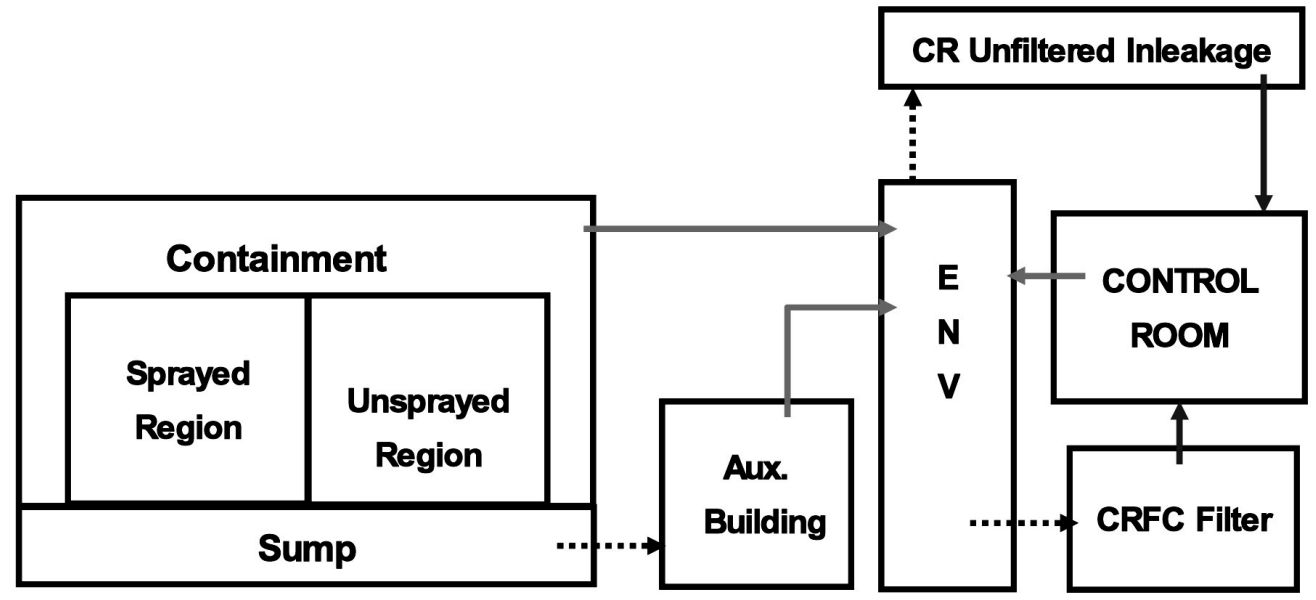

Fig. 1. Main Flow Path of LOCA (Loss Of Coolant Accident)

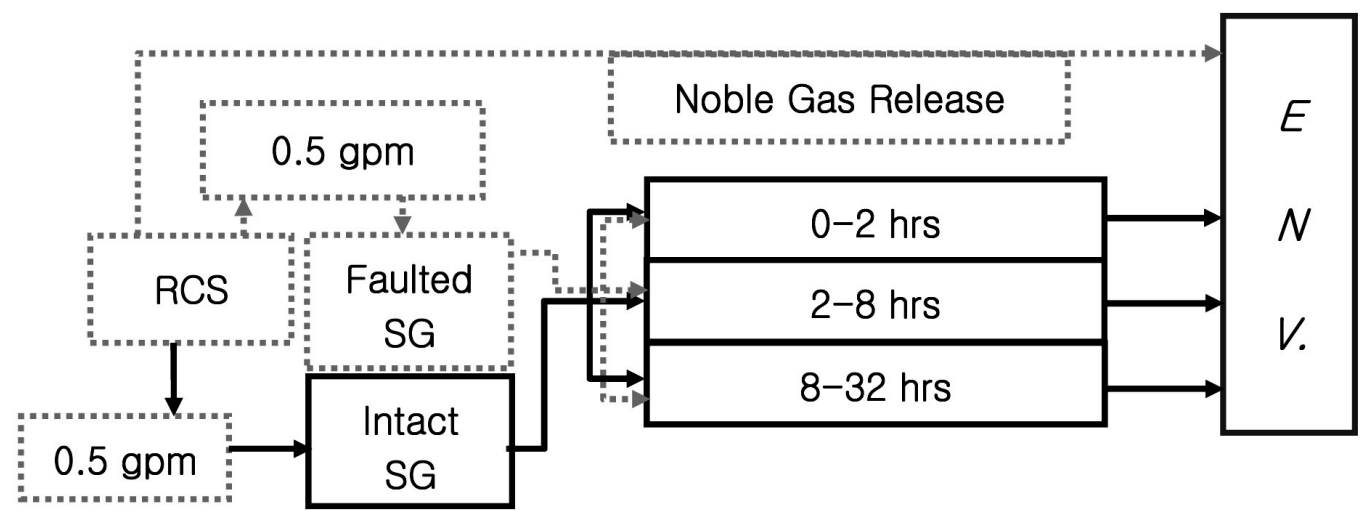

Fig. 2. Main Flow Path of Locked Rotor Accident 
Box-Muller's method is shown in term (7) and term (8). -Normal Distribution

$$
\begin{aligned}
& \mathrm{R} 1=\operatorname{random}(0,1), \mathrm{R} 2=\operatorname{random}(0,1) \\
& \mathrm{X} 1=s \times \sqrt{-2 \operatorname{Ln}(R 1)} \times \cos (2 \pi \mathrm{R} 2)+\mathrm{m} \\
& \mathrm{X} 2=s \times \sqrt{-2 \operatorname{Ln}(R 2)} \times \cos (2 \pi \mathrm{R} 1)+\mathrm{m} \\
& \mathrm{D}=\mathrm{L} \times \operatorname{random}(0,1)-0.5+\mathrm{m}
\end{aligned}
$$

-Log-Normal Distribution

$$
\begin{aligned}
& \mathrm{R} 1=\operatorname{random}(0,1), \mathrm{R} 2=\operatorname{random}(0,1) \\
& \mathrm{X} 1=\operatorname{Ln}(s \times \sqrt{-2 \operatorname{Ln}(R 1)} \times \cos (2 \pi \mathrm{R} 2)+\operatorname{Ln}(\mathrm{m})) \\
& \mathrm{X} 2=\operatorname{Ln}(s \times \sqrt{-2 \operatorname{Ln}(R 2)} \times \cos (2 \pi \mathrm{R} 1)+\operatorname{Ln}(\mathrm{m})) \\
& \mathrm{D}=\mathrm{L} \times \operatorname{Ln}[\operatorname{random}(0,1)] \times \mathrm{Skew}+\operatorname{Ln}(\mathrm{m})
\end{aligned}
$$

\subsection{Sensitivity Analysis}

In order to determine the key impact parameters of limiting cases, a sensitivity analysis is conducted with the physical parameters, plant design parameters, and the numerical model of RADTRAD.

In this sensitivity analysis, it is necessary to select a reference case that provides a basis for various parametric studies.

The conditions and assumptions of the reference case are listed in Table 7. These references are based on the FSAR of Kori Unit 1. All parameters of Table 7 are wellknown, necessary elements used in the input deck of the safety analysis [1-5]. The approach is essentially based on the relevancy of a parameter to the dose calculation and the extent to which the parameter influences the peak dose calculations. A quantity called "NDD (Normalized Dose Difference)" is used as follows as an "indicator" or a "sensitivity index" of the impact parameters:

$$
\mathrm{NDD}=\left(\mathrm{D}_{\text {high }}-\mathrm{D}_{\text {low }}\right) / \mathrm{D}_{\text {base }} \times 100 \%
$$

where, $\mathrm{R} 1, \mathrm{R} 2$, and random $(0,1)$ are uniform random numbers and " $\mathrm{Ln}$ " is natural $\log$.

In algorithms (7) and (8), $\mathrm{m}$ is the design parameter of Kori Unit 1.

Skew in a log-normal distribution is used for a nonsymmetric specification as a "log-normal shape factor" ranging from 1 to 2 .

The results of the Monte Carlo simulation method are compared with Emmanuel Porcheron's experiment results. The variable distributions are then used for evaluating the parameter uncertainty of the RADTRAD dose model applied to Kori Unit 1. All processes of the uncertainty assessment in this study are shown in Fig. 3.

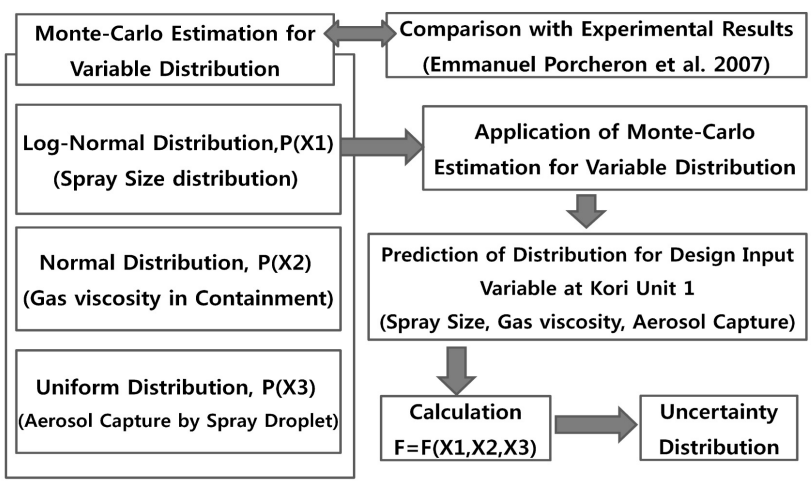

Fig. 3. Process for Uncertainty Assessment in Fission Product Removal Model of RADTRAD Code used in Kori Unit 1
In equation (9), ( $\left.D_{\text {high }}-D_{\text {low }}\right)$ is the range of the dose calculated when the parameter is set at its highest and lowest values, and $D_{\text {base }}$ is the dose when the parameter is set at its reference value. The base value uses a well referenced parameter value from the FSAR of Kori Unit 1 and the relevant radionuclide sources.

\subsection{Estimation of Safety Margin}

The summary in Table 8 and Table 9 shows an expansion of the conditions of sensitivity for reliable operation in the cases of LOCA and LRA. These conditions are used for estimating the safety margin of LOCA and LRA. For LOCA, iodine chemical form, timing release, and dose conversion factor are selected to estimate the safety margin. For LRA, in order to evaluate the operating safety margin, the selected parameters are gap fraction, fuel failure, partitioning fraction, and the leakage between primary coolant and secondary coolant.

\section{RESULTS AND DISCUSSION}

\subsection{Conservatism and Uncertainty of RADTRAD Code in These Analyses}

The iodine removal model of RADTRAD used for the conservatism analysis is based on the phenomena and correlation from a spray nozzle performance test of ORNL. This model includes the mechanisms for spray and natural deposition. In particular, the RADTRAD mathematical model has the same pattern compared with the US NRC SRP model. The sole difference between these models is 
Table 7. Reference Values of Parameters for Sensitivity Analysis at Kori Unit 1 Under LOCA and LRA

\begin{tabular}{|c|c|c|c|}
\hline Accident & System & Parameters & Reference \\
\hline \multirow{12}{*}{ LOCA } & \multirow{3}{*}{ Containment } & Leak rate & $0.1 \% /$ day \\
\hline & & Spray removal & $16.3 \mathrm{hr}^{-1}$ \\
\hline & & Mixing rate & $2.000 \times 10^{4}$ \\
\hline & \multirow{3}{*}{ ESF } & Iodine partitioning & $10 \%$ \\
\hline & & Sump leakage & $0.17 \times 10^{-2} \mathrm{cfm}$ \\
\hline & & HVAC flow & $3600 \mathrm{cfm}$ \\
\hline & \multirow{3}{*}{$\begin{array}{c}\text { RADTRAD } \\
\text { Numerical Model }\end{array}$} & Natural Deposition & $1.5 \mathrm{hr}^{-1}$ \\
\hline & & Henry's model (Natural deposition model) & $1.1 \mathrm{hr}^{-1}$ \\
\hline & & Decontamination Factor & 200 \\
\hline & \multirow{3}{*}{$\begin{array}{l}\text { Source Term } \\
\text { Characteristics }\end{array}$} & Dose Conversion Factor & ICRP 2 \\
\hline & & Timing Release & Puff model \\
\hline & & Iodine Type & Aerosol \\
\hline \multirow{7}{*}{ LRA } & \multirow{4}{*}{$\begin{array}{l}\text { Primary \& } \\
\text { Secondary } \\
\text { (leak rate) }\end{array}$} & Primary to Secondary leakage & $0.5 \mathrm{gpm}$ per $\mathrm{SG}$ \\
\hline & & Gap fraction & R.G. 1.25 \\
\hline & & Fuel failure & $65 \%$ \\
\hline & & Iodine Partitioning & $10 \%$ \\
\hline & \multirow{3}{*}{$\begin{array}{c}\text { Source Term } \\
\text { Characteristics }\end{array}$} & Dose Conversion Factor & ICRP 2 \\
\hline & & Timing Release & Puff model \\
\hline & & Iodine Type & Aerosol \\
\hline
\end{tabular}

ESF : Emergency Safety Facility

HVAC: Heating Ventilation \& Air Conditioning System

Table 8. Conditions for Estimation of Safety Margin Under LOCA

\begin{tabular}{|c|c|c|c|c|c|c|}
\hline Case No. & $\begin{array}{l}\text { Base of the } \\
\text { parameters }\end{array}$ & $\begin{array}{c}\text { Melted Core } \\
(\%)\end{array}$ & $\mathrm{DCF}^{*}$ & $\begin{array}{l}\text { Timing } \\
\text { Release }\end{array}$ & $\begin{array}{c}\text { Iodine Chemical } \\
\text { Form } * *\end{array}$ & $\begin{array}{c}\text { Source } \\
\text { Term }\end{array}$ \\
\hline 1 & FSAR & 100 & 1 & No & $\mathrm{E}$ & TID \\
\hline 2 & FSAR & 100 & 1 & Yes & $\mathrm{E}$ & AST \\
\hline 3 & FSAR & 100 & 2 & No & $\mathrm{E}$ & AST \\
\hline 4 & FSAR & 100 & 2 & Yes & $\mathrm{E}$ & AST \\
\hline 5 & FSAR & 100 & 2 & Yes & $\mathrm{P}$ & AST \\
\hline
\end{tabular}

* : 1(ICRP-2), 2(ICRP-30), ** : E(elemental), P(particulate)

that the RADTRAD model has been developed by a Monte Carlo uncertainty estimation. In contrast, the SRP model has been developed by experimental results and conservative assumptions.
Although these models differ in terms of the methodology for their development, in this work, to verify the feasibility of RADTRAD code, the conservatism and the uncertainty between the RADTRAD model and SRP 
Table 9. Conditions for Estimation of Safety Margin Under LRA

\begin{tabular}{|c|c|c|c|c|c|c|c|}
\hline Case No. & $\begin{array}{l}\text { Base of the } \\
\text { parameters }\end{array}$ & $\begin{array}{l}\text { Fuel Failure } \\
\qquad(\%)\end{array}$ & Gap Fraction* & $\begin{array}{c}\text { Part. } \\
\text { Fraction }\end{array}$ & $\begin{array}{c}\text { Iodine Chemical } \\
\text { Form** }\end{array}$ & $\begin{array}{c}\text { Leak } \\
\text { Rate }^{* * *}\end{array}$ & $\begin{array}{c}\text { Source } \\
\text { Term }\end{array}$ \\
\hline 1 & FSAR & 100 & 1 & 0.01 & $\mathrm{E}$ & 1.00 & TID \\
\hline 2 & FSAR & 100 & 2 & 0.01 & $\mathrm{E}$ & 1.00 & TID \\
\hline 3 & FSAR & 65 & 2 & 0.01 & $\mathrm{E}$ & 0.35 & TID \\
\hline 4 & FSAR & 65 & 2 & 0.01 & $\mathrm{P}$ & 1.00 & AST \\
\hline 5 & FSAR & 65 & 2 & 0.01 & $\mathrm{E}$ & 1.00 & AST \\
\hline 6 & FSAR & 65 & 2 & 0.01 & $\mathrm{E}$ & 1.00 & TID \\
\hline 7 & FSAR & 65 & 2 & 1.00 & $\mathrm{E}$ & 1.00 & TID \\
\hline 8 & FSAR & 65 & 2 & 1.00 & $P$ & 1.00 & AST \\
\hline 9 & FSAR & 100 & 2 & 0.01 & $P$ & 1.00 & AST \\
\hline 10 & FSAR & 100 & 2 & 0.01 & $\mathrm{E}$ & 1.00 & AST \\
\hline 11 & FSAR & 100 & 3 & 0.01 & $\mathrm{E}$ & 1.00 & TID \\
\hline 12 & FSAR & 100 & 3 & 0.01 & $\mathrm{P}$ & 0.35 & AST \\
\hline 13 & FSAR & 100 & 3 & 0.01 & $P$ & 1.00 & AST \\
\hline
\end{tabular}

* : 1(FSAR Best estimation), 2(R.G. 1.25), 3(R.G. 1.183)

** : E(elemental), $\mathrm{P}($ particulate), ***: Primary to secondary leak rate (gpm: gallon per minute)
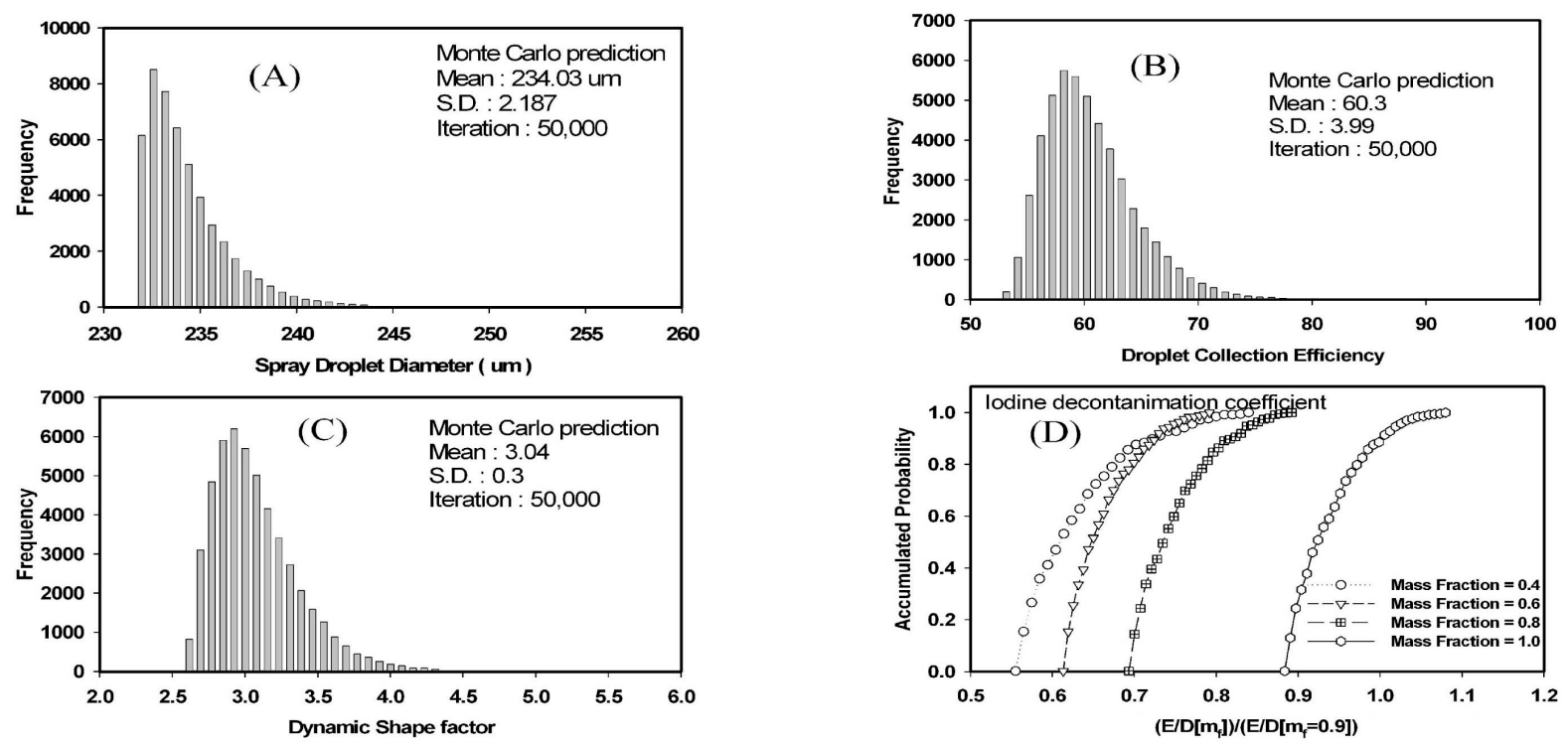

Fig. 4. Uncertainty Results of RADTRAD in Spray Removal Model (A,B,C : Variable Distribution from MC Prediction, D: Accumulated Probability (Percentile) of Iodine Decontamination Coefficient by Mass Fraction in Containment)

model are evaluated by using the mass fraction of containment $\left(\mathrm{m}_{\mathrm{f}}\right)$, and the natural deposition rate.

In this study, in order to estimate the uncertainty of the RADTRAD model, the droplet size distribution (spary flux Q), the collection efficiency of spray droplet (the influence factor of the spray droplets fall distance $h$ ), and iodine decontamination coefficients $\left(\mathrm{m}_{\mathrm{f}}\right)$ are simulated by using the MC (Monte Carlo) method. Figs. 3 and 4 present the results from the MC simulation based on the method outlined in Section 2.6. The MC method is very 
Table 10. Verification of Monte Carlo Simulation Prediction for Variable Distribution

\begin{tabular}{c|c|c|c|c}
\hline \multicolumn{4}{c}{ Comparison between experimental study results and MC calculation of this work } \\
\hline Methods & Statistics & $\begin{array}{c}\text { Spray Droplet Diameter } \\
\text { (um) }\end{array}$ & $\begin{array}{c}\text { Droplet Collection } \\
\text { Efficiency }\end{array}$ & Dynamic Shape Factor \\
\hline Experimental & Mean & 234 & 60 & 3.04 \\
Study[4, 5] & Standard Deviation & 2.196 & 4 & 0.3 \\
\hline MC Calculation & Mean & $234.01(1.0)$ & $60.00(1.0)$ & $3.04(1.0)$ \\
(in this study) & Standard Deviation & $2.187(0.995)$ & $3.99(0.997)$ & $0.30(1.0)$ \\
\hline MC & Min & 231.37 & 52.15 & 2.54 \\
Statistic & Max & 255.64 & 92.59 & 5.71 \\
Calculation & Lower CI & 231.71 & 54.74 & 2.67 \\
(in this work) & Upper CI & 238.29 & 67.50 & 3.61 \\
& Confidence Interval & $95.00 \%$ & $95.00 \%$ & $95.00 \%$ \\
& Skew & 1.73 & 0.99 & 5.26 \\
\end{tabular}

( ): ratio between experiment results and MC simulation[MC simulation/experiment result]
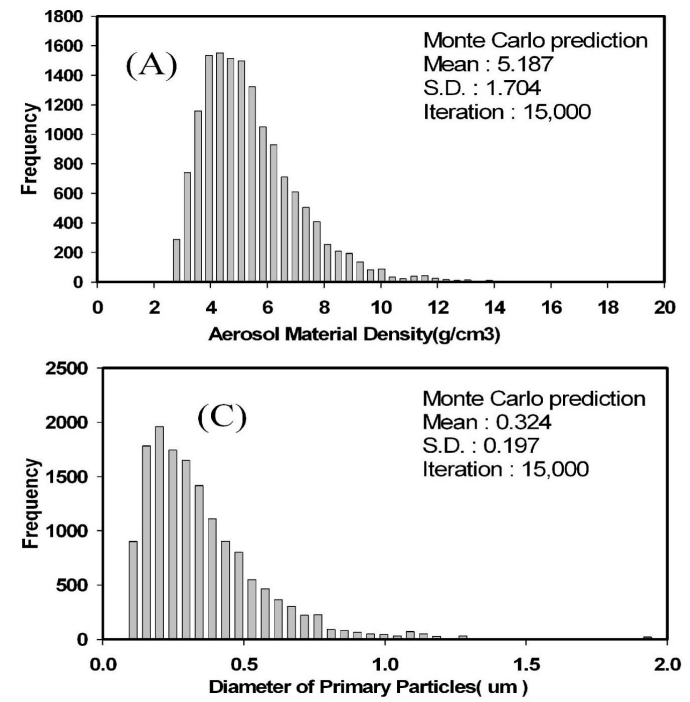
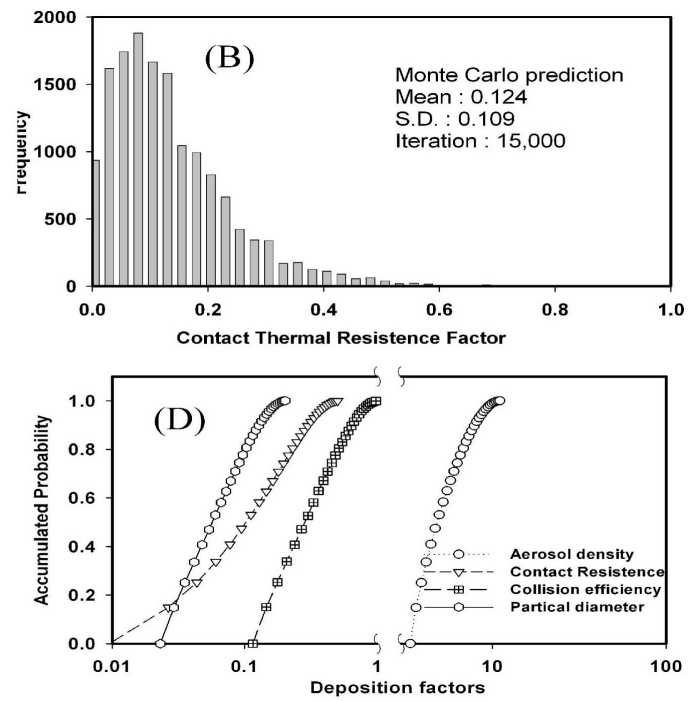

Fig. 5. Uncertainty Results of RADTRAD in Natural Deposition Model (A,B,C : Variable Distribution from MC Prediction, D: Accumulated Probability (Percentile) of Fission Product Deposition Factor in Containment)

well suited to predict the features and the behavior of spray droplets. In Table 10, the MC results derived in this study are compared with Porcheron's spray experimental results and Power M.A.'s experimental results. The difference between the MC prediction and experiment's results is within an error range of $0.05 \%$. $\sim 0.1 \%$. Here, for the design variables (droplet size, collection efficiency of droplet, and dynamic shape factor) of Kori Unit 1, it is assumed that their distributions correspond with the distributions generated from the MC method. The uncertainty distributions generated by this assumption are shown in Fig. 4 and Fig. 5.

In this work, the strategy for comparing this work (RADTRAD model) with the SRP model entails correlating the values of $\mathrm{E} / \mathrm{D}\left(\mathrm{m}_{\mathrm{f}}=0.9\right)$ using the method of NUREG/CR-5966. The ratios, $\mathrm{E} / \mathrm{D}\left(\mathrm{m}_{\mathrm{f}}\right) / \mathrm{E} / \mathrm{D}\left(\mathrm{m}_{\mathrm{f}}=0.9\right)$ at 


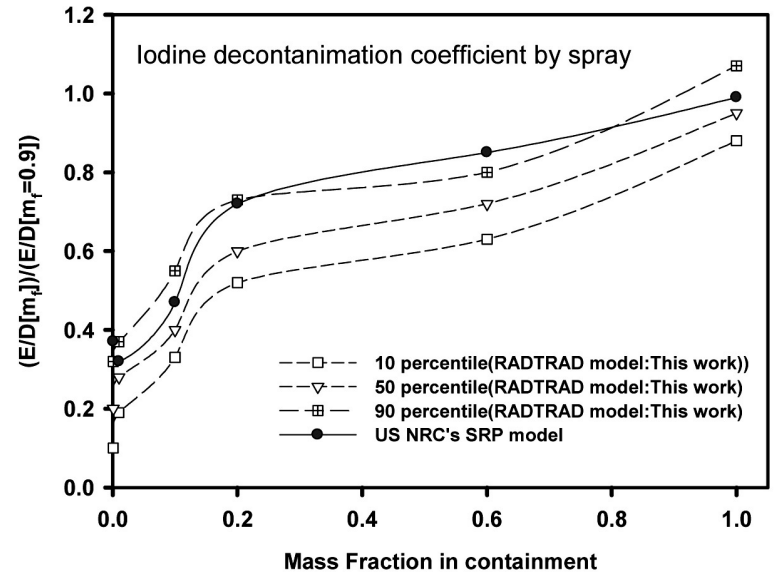

Fig. 6. Comparison Between RADTRAD Model and SRP Model in Spray Removal

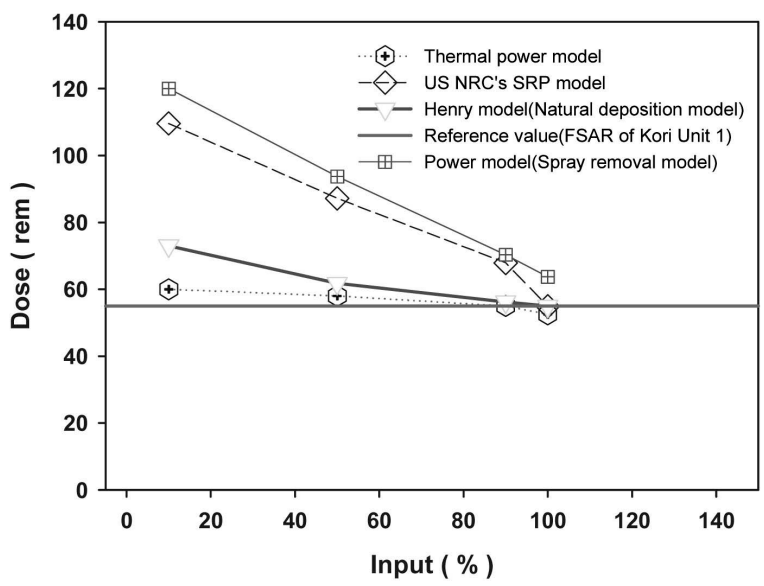

Fig. 8. Comparison Between RADTRAD and SRP in Modeling

specific percentiles in the distribution are then correlated with $\mathrm{m}_{\mathrm{f}}$ and $\mathrm{Q}$. Here, spray flux $\mathrm{Q}=0.0012 \mathrm{~m}^{3} / \mathrm{m}^{2}-\mathrm{s}$ and $\mathrm{a}$ droplet fall distance $\mathrm{h}=19.2 \mathrm{~m}$ are used for the comparison of RADTRAD and SRP. These inputs are derived from the FSAR (Final Safety Analysis Report) of Kori Unit1.

Fig. 6 shows the conservatism and uncertainty of this work for the spray removal condition.

In the RADTRAD model, the 10th percentile and 90th percentile are used as the lower bound and upper bound, respectively, in the uncertainty distribution. In this work, 50 percentile values are used for comparison with the SRP model.

The iodine decontamination coefficient of the RADTRAD model is lower than that of the SRP model in the case of the 50th percentile. This indicates that the RADTRAD model is more conservative than the SRP

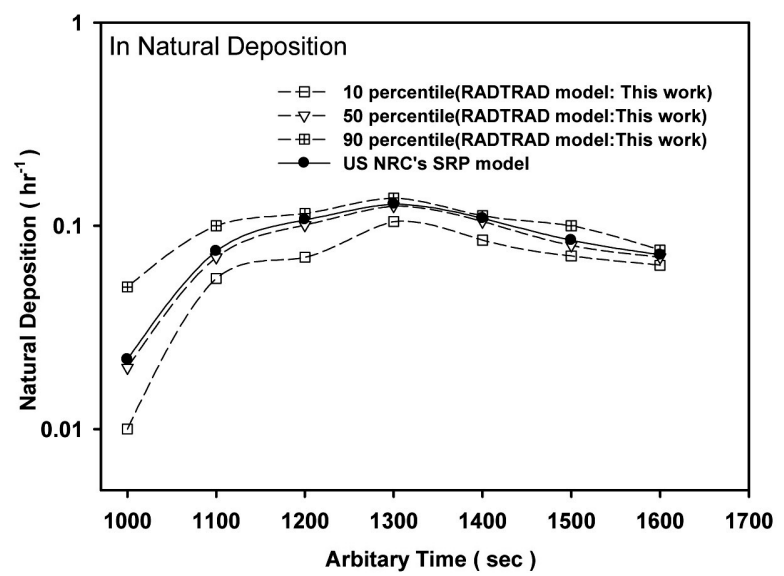

Fig. 7. Conservatism of RADTRAD Model Compared with SRP Model in Deposition

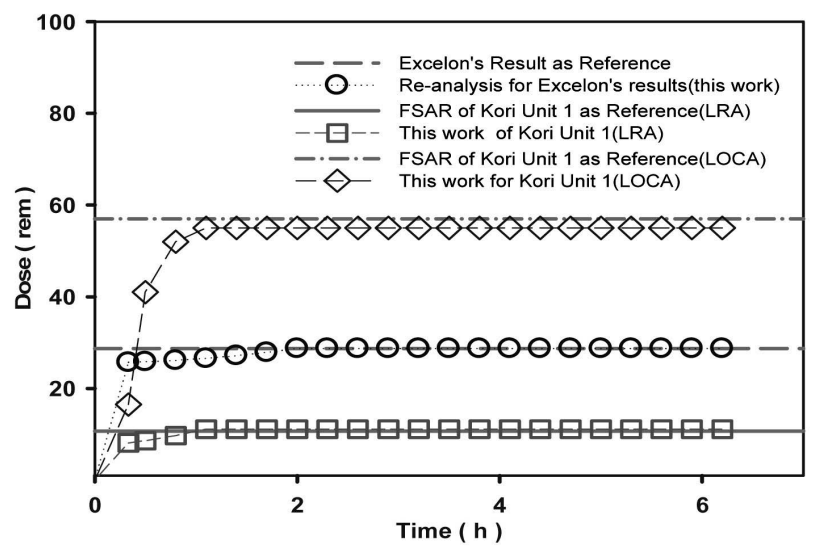

Fig. 9. Comparison Between the References and Calculations in this Study

model, because the lower the decontamination efficient, the higher the iodine remaining fraction in containment. In selecting the 50th percentile, the conservatism of the RADTRAD model is roughly $20 \%$ greater than that of the SRP model. As shown in Fig. 6, the RADTRAD model has uncertainty of about $10 \%$ in the range between the 50th percentile and 90th percentile. Otherwise, Fig. 7 shows that the natural deposition model of RADTRAD is similar to that of the SRP model. This result for natural deposition is attributed to the same mechanism being used in the natural deposition models of both RADTRAD and SRP. In the natural deposition model, the mechanism of SRP includes gravitational deposition, collision, condensation, and turbulence. These mechanisms are reflected in the RADTRAD model under the same conditions. 
Table 11. Verification of Calculations in this Study Through Comparison with USNRC's Example and Braidwood Units $3 \& 4$ (Values in Brackets are the Fraction of These Calculations Divided by the Braidwood and USNRC's Example)

\begin{tabular}{c|c|c|c|c}
\hline \multirow{2}{*}{$\begin{array}{c}\text { Items } \\
\text { (Dose: rem) }\end{array}$} & Braidwood & $\begin{array}{c}\text { Calculations } \\
\text { in this study }\end{array}$ & $\begin{array}{c}\text { CSNRC's Example } \\
\text { (Test 24) }\end{array}$ & $\begin{array}{c}\text { Calculations } \\
\text { in this study }\end{array}$ \\
\cline { 2 - 5 } & 0.1454 & $0.1453(0.999)$ & - & - \\
\hline Whole body & 28.7 & $28.7(1.0)$ & 68.6 & $69.3(1.01)$ \\
\hline Thyroid & 1.42 & $1.43(1.007)$ & 4.54 & $4.55(1.002)$ \\
\hline TEDE &
\end{tabular}

Table 12. Verification of Calculations in this Study for FSAR of Kori Unit 1 in Korea

\begin{tabular}{c|c|c|c}
\hline \multicolumn{2}{c|}{ Items (Dose : rem) } & Reference (FSAR of Kori Unit 1) & Calculations in this study (RADTRAD ) \\
\hline \multirow{3}{*}{ LRA } & Whole body & 0.25 & 0.22 \\
\cline { 2 - 4 } & Thyroid & 10.7 & 10.9 \\
\cline { 2 - 4 } & TEDE & - & 1.17 \\
\hline \multirow{3}{*}{ LOCA } & Whole body & 2.3 & 2.25 \\
\cline { 2 - 4 } & Thyroid & 57.0 & 55.5 \\
\cline { 2 - 4 } & TEDE & - & 4.3 \\
\hline
\end{tabular}

Fig. 6 and Fig. 7 show that the RADTRAD code is based on the SRP model and its similarity is available to conduct safety analyses.

Fig. 8 shows the sensitivity of the RADTRAD models. Among the models, the effect of the power model is greater than that of the other models. Also, the power model of RADTRAD is very similar to the SRP model in terms of the trend of the slop. Fig. 8 shows that, with respect to conservatism, RADTRAD can be used for dose calculation.

\subsection{Verification of Dose Calculation}

For verification of the results in this work, the calculations using RADTRAD code are performed under the same parameters conditions of Kori Unit 1. Other verifications are performed for Braidwood Nuclear Power Plant Unit 1 and the USNRC example "Test 24" reported in NUREG/CR-6604 under the same conditions. The comparative results, which are listed in Table 11 and Table 12, confirm that the accuracy of the calculations is within $1.0 \%$.

Fig. 9 shows that the calculated results verify the feasibility of the calculation in terms of the timing of the LOCA and the LRA (where symbol marks such as circle, square, and diamond shape represent the results in this work and the simple lines represent the results of the reference). The results confirm that the radiation dose is equivalent to the reference values within 2 hours of the accident.

\subsection{Results of Sensitivity Analysis}

Table 13 summarizes the overall sensitivity analysis results on limiting cases and the calculation models of RADTRAD. In order to calculate NDD, parameters between $1 \%$ and $100 \%$ of each reference value (the results of FSAR conditions) are used for calculating dose. For the calculated dose, maximum value is $D_{\text {high }}$ and the minimum value is $\mathrm{D}_{\text {low }}$. The most significant impact is the partitioning factor of the LOCA, and the gap fraction of the LRA.

Table 13 shows that the TID methodology depends strongly on iodine behavior, whereas the AST methodology depends solely on physical characteristics such as the leak rate, fuel failure and timing release.

Accordingly, the NDD of AST is generally less than that of TID. The results based on Table 13 are shown in Fig. 10 and Fig. 11.

Fig. 10 and Fig. 11 show that TID is greater than 
Table 13. NDD (Sensitivity Index) of Parameters for LOCA and LRA

\begin{tabular}{|c|c|c|c|c|c|c|}
\hline DBAs & System & Parameters & $\begin{array}{c}\text { TID:Dose Range } \\
\left(\mathrm{D}_{\text {low }} \sim \mathrm{D}_{\text {high }}\right) \\
\text { rem }\end{array}$ & $\begin{array}{c}\text { AST:Dose Range } \\
\left(\mathrm{D}_{\text {low }} \sim \mathrm{D}_{\text {high }}\right) \\
\text { rem }\end{array}$ & $\begin{array}{c}\text { TID } \\
\text { (NDD) \% }\end{array}$ & $\begin{array}{c}\text { AST } \\
\text { (NDD) } \%\end{array}$ \\
\hline \multirow{12}{*}{ LOCA } & \multirow{3}{*}{ Containment } & Leak rate & $1.71 \sim 57.0$ & $0.17 \sim 4.3$ & 97 & 96 \\
\hline & & Iodine removal & $33.46 \sim 57.0$ & $3.68 \sim 4.3$ & 41.3 & 15 \\
\hline & & Mixing rate & $51.76 \sim 57.0$ & $3.98 \sim 4.3$ & 9.2 & 7.3 \\
\hline & \multirow{3}{*}{ ESF } & Partitioning factor & $0.058 \sim 57.0$ & $0.128 \sim 4.3$ & 99.9 & 97 \\
\hline & & Sump leakage & $56.89 \sim 57.0$ & $4.26 \sim 4.3$ & 0.2 & 0.1 \\
\hline & & HVAC flow & $56.89 \sim 57.0$ & $4.26 \sim 4.3$ & 0.2 & 0.1 \\
\hline & \multirow{3}{*}{$\begin{array}{l}\text { RADTRAD } \\
\text { Calculation }\end{array}$} & Natural Deposition & $53.47 \sim 57.0$ & $3.97 \sim 4.3$ & 6.2 & 7.5 \\
\hline & & Henry's model & $52.27 \sim 57.0$ & $3.98 \sim 4.3$ & 8.3 & 7.2 \\
\hline & & $\mathrm{DF}^{*}$ & $22.29 \sim 57.0$ & $3.50 \sim 4.3$ & 60.9 & 18.3 \\
\hline & \multirow{3}{*}{ Source Term } & DCF** & $34.94 \sim 57.0$ & $2.54 \sim 4.3$ & 38.7 & 41.0 \\
\hline & & Release Timing & $45.6 \sim 57.0$ & $3.53 \sim 4.3$ & 20 & 17.9 \\
\hline & & Iodine chemical form & $55.29 \sim 57.0$ & $0.41 \sim 4.3$ & 3 & 90.5 \\
\hline \multirow{8}{*}{ LRA } & \multirow{5}{*}{$\begin{array}{l}\text { Primary to } \\
\text { Secondary }\end{array}$} & $\mathrm{DF}^{*}$ & $10.6 \sim 10.7$ & $1.08 \sim 1.17$ & 0.9 & 0.7 \\
\hline & & Leakage & $2.14 \sim 10.7$ & $0.49 \sim 1.17$ & 80 & 58 \\
\hline & & Gap fraction & $0.01 \sim 10.7$ & $0.01 \sim 1.17$ & 100 & 100 \\
\hline & & Fuel failure & $0.01 \sim 10.7$ & $0.01 \sim 1.17$ & 100 & 100 \\
\hline & & Partitioning factor & $1.05 \sim 10.7$ & $0.965 \sim 1.17$ & 90.1 & 17.5 \\
\hline & \multirow{3}{*}{ Source Term } & $\mathrm{DCF}^{* *}$ & $6.45 \sim 10.7$ & $1.045 \sim 1.17$ & 39.7 & 10.7 \\
\hline & & Release Timing & $8.56 \sim 10.7$ & $0.948 \sim 1.17$ & 20 & 19 \\
\hline & & Iodine chemical form & $10.64 \sim 10.7$ & $1.164 \sim 1.17$ & 0.5 & 0.5 \\
\hline
\end{tabular}

*: Decontamination Factor, **: Dose Conversion Factor

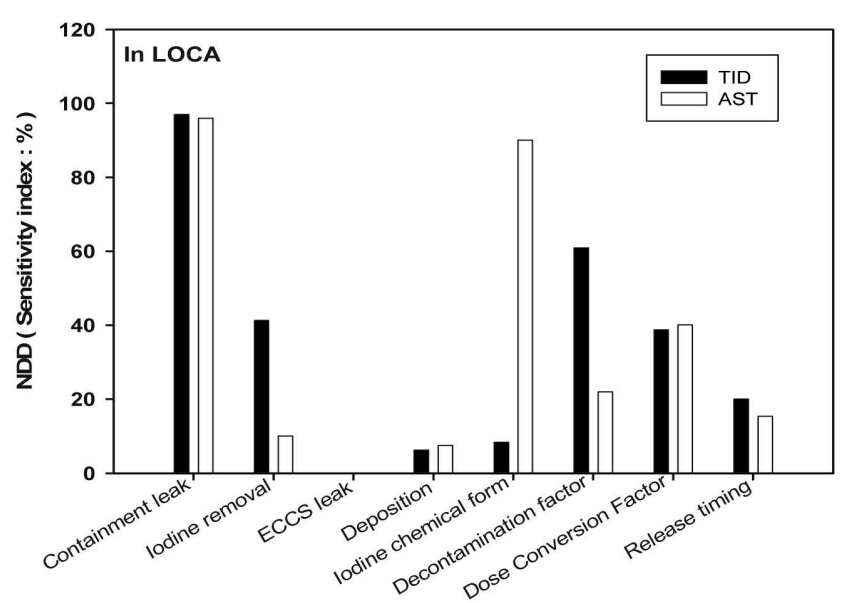

Fig. 10. Impact of Parameters Under LOCA

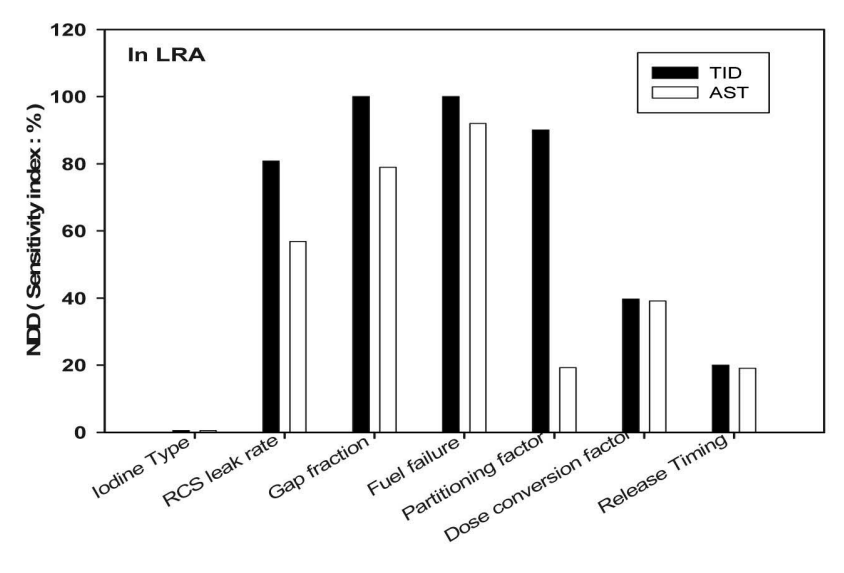

Fig. 11. Impact of Parameters Under LRA 
AST with regard to the impacts for iodine removal, decontamination factor, and partitioning factor. In particular, iodine removal and partitioning factor are more significant than any other parameters. The results from Fig. 10 and Fig. 11 are based on the iodine behavior. In the TID methodology, the weight of dose is concentrated on iodine. Moreover, Fig. 12 shows that the iodine impact of TID is 10-fold greater than that of AST. This is due to the assumptions employed for TID and the concept of ICRP 2, which is based on the concept of human's target organ. According to this concept, all of the iodine is deposited at the thyroid, and the iodine chemical form is gas phase or elemental type.

In contrast to the TID, AST is characterized by realistic and physical behavior of radioactivity in containment. It specifies a categorized release in terms of phenomenological accidental phase and also defines that the dominant form of the fission product iodine is air-bone particulate. Therefore, in a LOCA, the iodine release to the containment is aerosol form (air-bone particulate, particulate). The principal mechanisms that remove particulate from the in-containment are containment spray and natural deposition.

In case of the AST, containment sprays are more effective than TID in reducing the particulate iodine as well as other particulates. In this work, the iodine chemical form of Fig.10 shows that the particulate removal of AST by spray is more dominant than any other impact element. These results mean that the iodine particulate form and the other fission products of AST onto spray droplets and the natural removal process remain constant due to mechanical collection by spray. In the US NRC recommendation, the particulate removal rate is larger than the gas phase

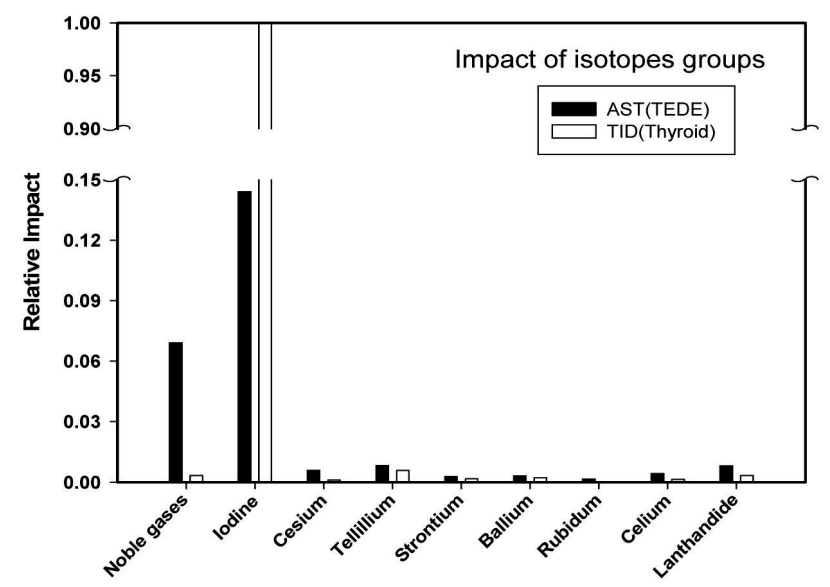

Fig. 12. Sensitivity for Isotope Groups removal rate by a factor of 10 . From the results of the application, in a LOCA, the safety margin of the AST is greatly increased in comparison with TID.

In a LRA, the key parameter is the partitioning factor, which is the ratio of the gas phase over the liquid phase in iodine physical form. This is due to the volatility of iodine. The volatility is applied to the RCS leak rate and the release rate of fission products into the environment. Fig. 11 shows that the iodine behavior in TID is greatly attributed to dose calculation. Fig. 12 verifies the results of Fig. 11.

Fig. 12 shows that the effect of iodine is very dominant among impact elements in isotopes groups. This shows that all about TID is generated from iodine behavior. Otherwise, AST shows that all kinds of isotopes are homogeneously distributed into the dose effect.

The results in Fig. 13 visualize the change width of dose for each input parameter. As with the previous results, in the design parameters, the containment leakage and the spray removal are dominant. These results are deeply relevant to the change of iodine behavior in the AST.

\subsection{Impact of Key Parameters for Safety Margin}

Table 14 and Fig. 14 show the representative types of selective application from the AST and full application of the AST. These considerations include the effect of DCF (Dose Conversion Factor), the source term of AST, the timing release, and the spray removal effect of full application of AST, named "case 5" in Fig. 14.

Fig. 14 shows that the margin of AST is increased by up to $95 \%$. This result is $15 \%$ larger than the margin of the AST in the reference case based on the FSAR of Kori Unit 1 . The safety margin increase of $15 \%$ is due to iodine particulate form and DCF (Dose Conversion Factor).

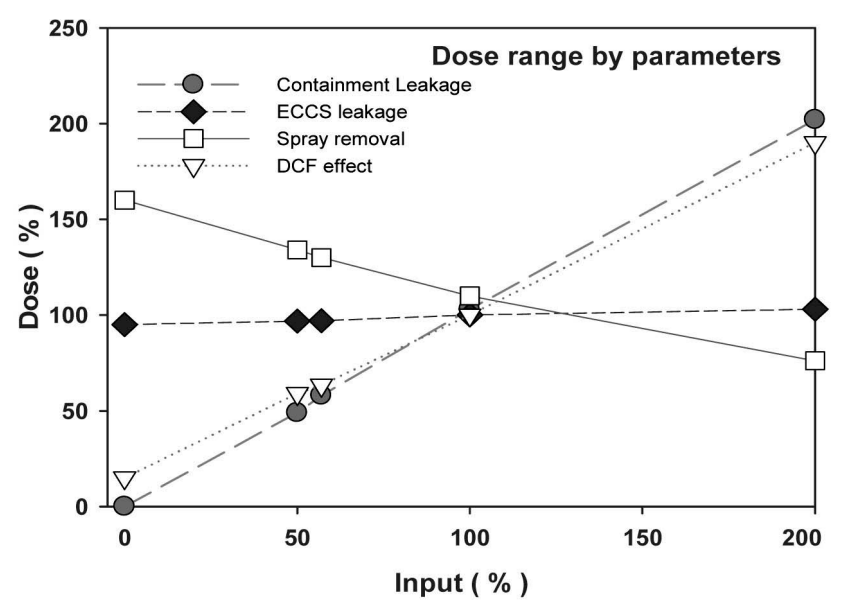

Fig. 13. Sensitivity of Parameters for Design 
Table 14. Results of the Safety Margin Analysis of LOCA for Kori Unit 1

\begin{tabular}{c|c|c|c|r}
\hline Case No. From Table 8 & Whole Body (rem) & Thyroid (rem) & TEDE (rem) & Source Term \\
\hline 1 & 1.3 & 55.5 & 4.1 & TID \\
\hline 2 & 1.3 & 55.5 & 4.3 & AST \\
\hline 3 & 0.7 & 35.5 & 3.80 & AST \\
\hline 4 & 0.88 & 33.0 & 2.75 & AST \\
\hline 5 & 0.55 & 30 & 1.25 & AST \\
\hline
\end{tabular}

Table 15. Results of the Safety Margin Analysis of LRA for Kori Unit 1

\begin{tabular}{c|c|c|c|c}
\hline Case No. From Table 9 & Whole Body (rem) & Thyroid (rem) & TEDE (rem) & Source Term \\
\hline 1 & 0.45 & 10.7 & 7.6 & TID \\
\hline 2 & 5.7 & 90 & - & TID \\
\hline 3 & 3.91 & 20 & 0.805 & TID \\
\hline 4 & 0.64 & 5.34 & 0.808 & AST \\
\hline 5 & 0.64 & 5.41 & 1.179 & AST \\
\hline 6 & 0.542 & 40.5 & 5.22 & TID \\
\hline 7 & 1.04 & 134 & 0.99 & TID \\
\hline 8 & 0.54 & 14.01 & 1.239 & AST \\
\hline 10 & 0.98 & 8.22 & 1.243 & AST \\
\hline 11 & 0.98 & 8.31 & 5.4 & AST \\
\hline 12 & 4.01 & 47.1 & 0.755 & TID \\
\hline
\end{tabular}

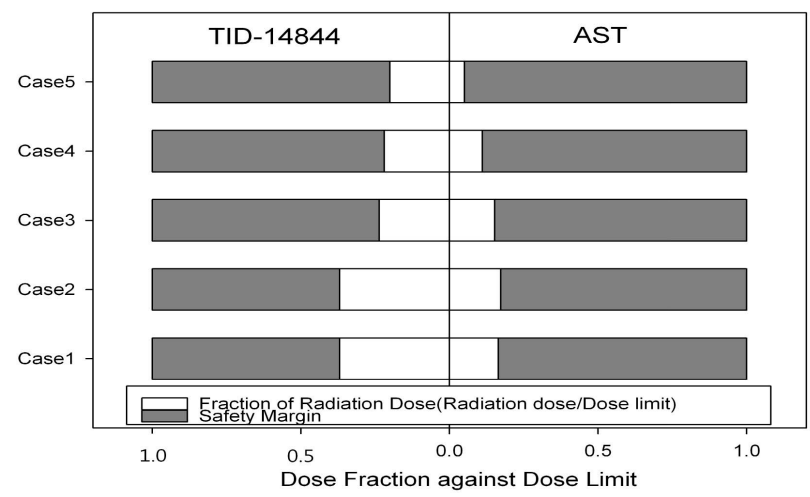

Fig. 14. Comparisons for Each Application of AST Under LOCA(Case1:Full Application of TID-14844,

Case2: Source Term Release of TID + ICRP2,

Case 3: Source Term Release of TID + ICRP30,

Case4: Source Term of TID + ICRP30 + Release Timing of AST, Case 5:Full Application of AST)

*Here, if using the Original TID Assumption of No-deposition on the Containment Surface, Thyroid dose is 112 Rem
In Fig. 14, case 5 includes the iodine particulate form and DCF in applying the AST methodology. Here, if the iodine particulate form is considered, the spray removal rate for the iodine particulate form is increased to 10-fold, corresponding with the typical PWR spray removal rate described in R.G. 1.183.

Table 15, which compares the results of Figs. 15 through 18, shows the case analysis for the whole body, thyroid, and TEDE of a LRA as a non-LOCA case. The results from Figs. 15 to 18 show that the partitioning fraction and the fuel failures are the most limiting conditions of the TID. In contrast, the AST applications show that the limiting conditions are the leak rate and the dose conversion factor. These results suggest that the thyroid of the TID depends strongly and exclusively on iodine and that the TEDE of the AST is affected by all kinds of fission products, such as the whole body dose. In addition, the minimum reduced dose of the AST is more than $60 \%$ greater compared with that of the TID values. In particular, 


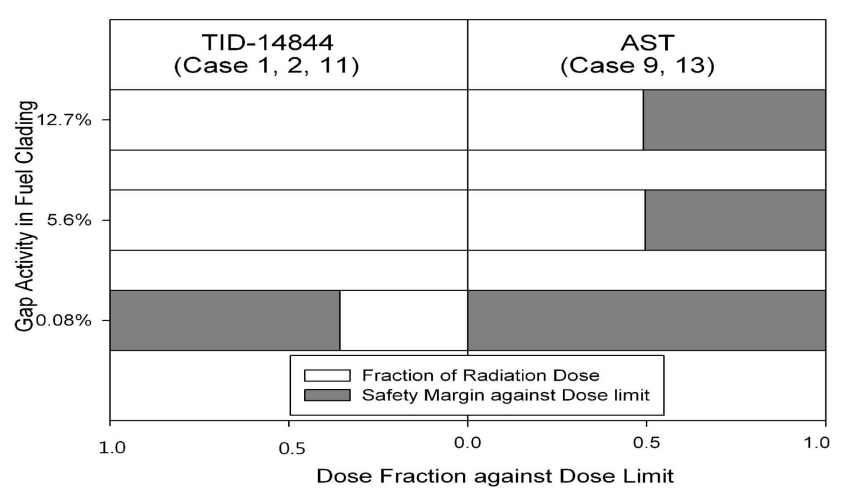

Fig. 15. Comparisons for Each Gap Activity Fraction

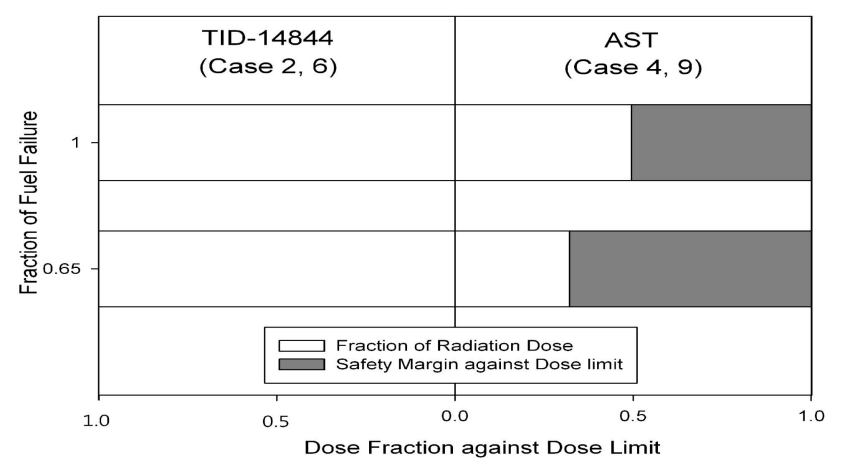

Fig. 17. Comparisons for Each Fuel Failure

the case in Fig. 16 shows that the AST at the leak rate of $0.35 \mathrm{gpm}$ has a margin of about $80 \%$ against the TEDE criteria. Figs. 17 and 18 show that AST specific effects are derived from all kind of fission products, as shown in Fig.11 and Fig.12 of the previous section. These results explain that the dose calculation is slightly dependent on the parameters relevant to iodine behavior such as partitioning fraction and fuel failure under the AST.

\section{CONCLUSION}

Based on this study, the following conclusions are made.

1. The conservatism and the uncertainty of the dose calculation method used in this study for AST application are evaluated using a Monte Carlo simulation and compared with the US NRC SRP model. Also, the uncertainty of the RADTRAD model is within $10 \%$ in the range between the upper bound (90th percentile) and the median value (50th percentile).

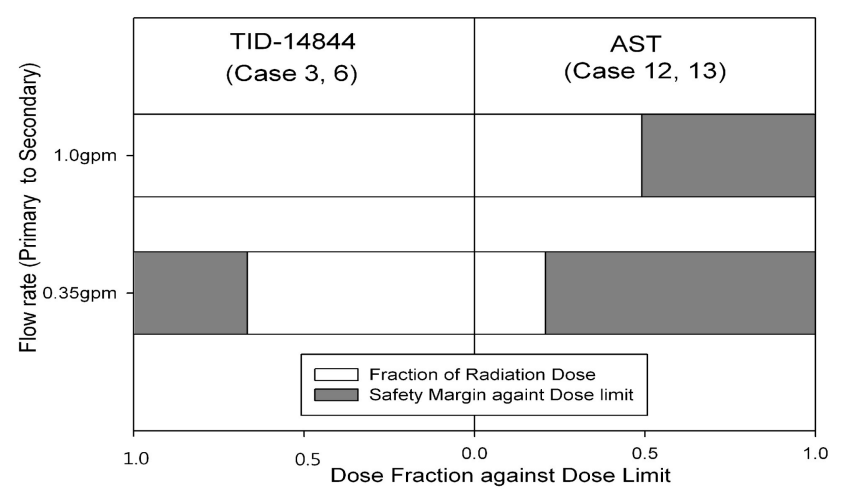

Fig. 16. Comparisons for Each Leak Flow Rate

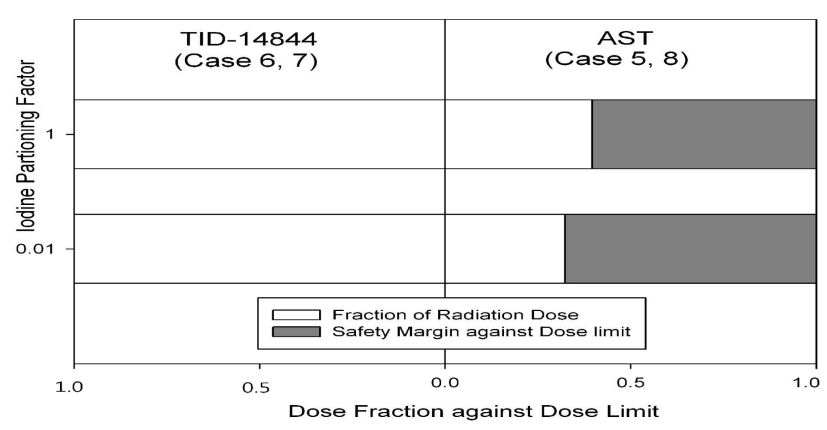

Fig. 18. Comparisons for Each Partitioning Fraction

2. The RADTRAD model used in this study is more conservative than the SRP model, by a factor of 0.8 .

3. According to the sensitivity analysis conducted in this study, the TID methodology depends strongly on the behavior of iodine, whereas the AST depends solely on physical characteristics such as leak rate, the gap fraction, and the fuel failure.

4. For the radionuclide behavior, the impact of iodine is 10 -fold greater in comparison with any other radionuclide in the TID methodology. In contrast, the AST is based on the homogeneous distribution of all kinds of isotopes in calculating dose, regardless of iodine behavior.

5. Full application of the AST is a very effective means of increasing the safety margin. In the case of a LOCA, the AST provides a margin of more than $95 \%$ against the dose criterion. In the case of TID, the safety margin is at most $60 \%$. Under a LRA accident, the safety margins of the AST and TID are $80 \%$ and $20 \%$, respectively. 


\section{REFERENCES}

[ 1 ] U.S. Atomic Energy Commission (now USNRC), Technical Information Document-14844, "Calculation of Distance Factors for Power and Test Reactor Sites", NRC's Public Electronic Reading Room, Accession number 8202010067, (1962).

[2 ] US. NRC, "Alternative Source Terms for Evaluating Design Basis Accidents at Nuclear Power Reactors", Regulatory Guide 1.183, (July 2000).

[ 3 ] USNRC, "Standard Review Plan for the Review of Safety Analysis Reports for Nuclear Power Plants," NUREG0800, (September 1981).

[4] Calculation DRE02-0036, "Re-analysis of Fuel Handling Accident (FHA) Using Alternative Source Terms", Dresden Unit 2\&3,(August 13, 2005).

[ 5 ] Porcheron, E., Lemaitre, P., Nuboer, V., Vendel, J., "Experimental investigation in the TOSOQAN facility of heat and mass transfers in a spray for containment application", Nuclear Engineering and Design, vol. 237, pp.1862 - 1871 (2007).

[6] Rimberg, D., Peng, Y., “Aerosol collection by Falling Droplet", Air Pollution Control and Design Hand book, (New York, 1977).

[7] Final Safety Analysis Report at Kori Unit 1 (revision in 2007).
[ 8 ] USNRC, "RADTRAD: A Simplified Model for Radionuclide Transport and Removal and Dose Estimation", NUREG/ CR-6604(April, 1998), Supplements 1(June 1999) and 2(October, 2002).

[9] American Nuclear Society, "American National Standard Radioactive Source Term for Normal Operation of Light Water Reactors", ANS/ANSI-18.1-1999, (1999).

[10] U.S. Federal Guidance Report No. 11 \& No. 12.(1988-1993).

[11] USNRC, "Assumptions Used for Evaluating the Potential Radiological Consequences," Regulatory Guide 1.4, Revision 2, (June 1974).

[12] USNRC, "Results of the Revised (NUREG-1465) Source Term Rebaselining for Operating Reactors," SECY-98154, (June 30, 1998).

[13] USNRC, “A Simplified Model of Aerosol Removal by Containment Sprays,” NUREG/CR-5966,( March 1993).

[14] USNRC, "A Simplified Model of Aerosol Removal by Natural Processes in Reactor Containments," NUREG/CR-6189, (March 1993).

[15] USNRC, "Assumptions Used for Evaluating the Potential Radiological Consequences,” Regulatory Guide 1.25, (March 1972).

[16] William H., Teukolsky, Saul A., Vetterling, William T., Flannery, Brain P., Numerical Receipes in C, Cambridge University Press (1992). 